\title{
Triple-negative breast cancer: A run-through of features, classification and current therapies (Review)
}

\author{
MEGHANA MANJUNATH $^{1,2}$ and BIBHA CHOUDHARY ${ }^{1}$ \\ ${ }^{1}$ Department of Biotechnology, Institute of Bioinformatics and Applied Biotechnology, Bengaluru, Karnataka 560100; \\ ${ }^{2}$ Manipal Academy of Higher Education, Manipal, Karnataka 576104, India
}

Received September 26, 2020; Accepted March 1, 2021

DOI: $10.3892 /$ ol.2021.12773

\begin{abstract}
Breast cancer is the most prevalent cancer in women worldwide. Triple-negative breast cancer (TNBC) is characterized by the lack of expression of estrogen receptor, progesterone receptor, and human epidermal growth factor receptor 2 . It is the most aggressive subtype of breast cancer and accounts for $12-20 \%$ of all breast cancer cases. TNBC is associated with younger age of onset, greater metastatic potential, higher incidence of relapse, and lower overall survival rates. Based on molecular phenotype, TNBC has been classified into six subtypes (BL1, BL2, M, MES, LAR, and IM). TNBC treatment is challenging due to its heterogeneity, highly invasive nature, and relatively poor therapeutics response. Chemotherapy and radiotherapy are conventional strategies for the treatment of TNBC. Recent research in TNBC and mechanistic understanding of disease pathogenesis using cutting-edge technologies has led to the unfolding of new lines of therapies that have been incorporated into clinical practice. Poly (ADP-ribose) polymerase and immune checkpoint inhibitors have made their way to the current TNBC treatment paradigm. This review focuses on the classification, features, and treatment progress in TNBC. Histological subtypes connected to recurrence, molecular classification of TNBC, targeted therapy for early and advanced TNBC, and advances in non-coding RNA in therapy are the key highlights in this review.
\end{abstract}

Correspondence to: Dr Bibha Choudhary, Department of Biotechnology, Institute of Bioinformatics and Applied Biotechnology, Biotech Park, Electronic City Phase 1, Bengaluru, Karnataka 560100, India

E-mail: vibha@ibab.ac.in

Abbreviations: TNBC, triple-negative breast cancer; FGFR, fibroblast growth factor receptor; ORR, overall response rate; OS, overall survival; PFS, progression free survival; PCT, physician's choice therapy

Key words: triple-negative breast cancer, targeted therapy, metastatic, overall response rate, clinical trials

\section{Contents}

1. Introduction

2. Histology-guided classification of TNBC

3. Multiomics-guided molecular classification of TNBC

4. Molecular aberrations in TNBC

5. Circulating tumor cells (CTCs) in TNBC

6. Conventional mode of treatment in TNBC

7. Emerging role of targeted therapy as a strategy to treat TNBC

8. Non-coding RNA as therapy

9. Conclusions

\section{Introduction}

Breast cancer is a heterogeneous disease with varying biological and clinical characteristics. It is the most common cancer among women worldwide, accounting for $25 \%$ of all cancer cases (1). According to GLOBOCAN 2020, the incidence and mortality of breast cancer reported worldwide were $34,65,951$ new cases and 11,21,413 deaths, respectively; in India, 1,204,532 new cases and 436,417 deaths were recorded in 2020 (2).

Immunohistochemical analysis of breast tumors is the gold-standard method used in clinics to classify them based on the hormone receptor expression for improved therapeutic decisions. Based on this, breast cancer can be broadly grouped into five types, namely: i) Progesterone receptor (PR)-positive, estrogen receptor (ER)-positive and human epidermal growth factor 2 (Her2)-negative (luminal A); ii) ER-positive, PR-positive/negative and Her2-positive (luminal B); iii) Her2-overexpressing, ER- and PR-negative; iv) ER-, PR- and Her2-negative (basal-like or triple-negative), and v) normal-like (expression status similar to luminal A and resemble normal breast profile) (3-5). Additionally, molecular breast cancer analysis identified a distinctive phenotype with low claudin expression, immune receptor, and EMT markers expression (6). Cancer types with the claudin ${ }^{\text {low }}$ phenotype are highly metastatic and associated with poor prognosis (7). Her2-overexpressing cancer also displays high metastasis and poor prognosis (8). Among ER-positive subtypes, luminal B is associated with a significantly worse prognosis than luminal A $(9,10)$. Patients with basal subtypes of cancer with BRCA1 mutations have a poor prognosis (9). 
Based on specific gene expression patterns, breast cancers are categorized into five intrinsic or molecular subtypes. Among the intrinsic subtypes, basal-like triple-negative breast cancer (TNBC) accounts for $12-20 \%$ of breast cancers (11). TNBC has drawn specific attention due to the lack of expression of all three receptors (ER, PR, and Her2). Thus, it cannot be treated using anti-estrogen hormonal therapies or trastuzumab (12). Morphologically, TNBC is characterized by hyperdense masses without calcification, usually occurring in women $<50$ years of age. Histological features include significant lymphocyte infiltration, central necrosis, pushing tumor borders, and fibrosis (13). Cytokeratins, fascin, epidermal growth factor receptor (EGFR), caveolin, and vimentin are usually expressed in basal-like TNBC $(14,15)$. TNBC is challenging to treat, as it is quite complex due to poor cell differentiation, molecular heterogeneity, and rapid metastasis, often leading to chemoresistance and recurrence of the disease (16). Fast relapse and invasions are common features of TNBC tumors and show poor prognosis (17). Recent advances in omics technologies have provided insight into the molecular mechanisms underlying TNBC (18). The present review focuses on the different subtypes of TNBC and therapeutic approaches currently employed in the treatment of TNBC.

\section{Histology-guided classification of TNBC}

Histologically, most TNBC is categorized as no special type (IDC-NST) (17). Most IDC is characterized by pleomorphic cells with prominent nucleoli. The cells are organized into diffuse sheets, cords, nests with ductal differentiation. The rest of the tumors are categorized into 47 specific subtypes, such as invasive lobular carcinoma (relatively common), metaplastic carcinoma, medullary carcinoma, mucinous carcinoma, adenoid cystic carcinoma, secretory carcinoma, acinic cell carcinoma, neuroendocrine tumors, as well as the rarest glycogen-rich clear cell carcinoma $(19,20)$.

Among these specific subtypes (Fig. 1), medullary breast carcinoma occurs in $<1 \%$ of patients and shows distinctive features, such as high lymphoplasmacytic infiltration, overexpression of BCLG (a pro-apoptotic gene); it bears more losses of heterozygosity than other subtypes and is immunomodulatory $(21,22)$. It is associated with better outcomes compared with other TNBC subtypes (22). Metaplastic carcinoma presents unique pathologic features, where the glandular component may be partially or completely replaced by a non-glandular component(s), and based on their differentiation status further divided into i) Squamous type, tumor with keratinization and squamous differentiation; ii) matrix-producing type, tumor with more cells in the periphery; iii) mixed type, tumor showing both squamous differentiation and large high-grade cells with pleomorphic nuclei; and iv) spindle-cell type, tumor with storiform-like spindle cells. These metaplastic tumors harbor mutations in the PIK3CA, Wnt (Wingless-Type MMTV Integration Site Family) signaling pathway genes and display a unique copy number alteration pattern (23-25). Adenoid cystic carcinoma (ACC) is characterized by the presence of dividing epithelial cells and myoepithelial cells producing mucinous membrane. ACC occurs in $0.1 \%$ of patients with basal-like features $(26,27)$ and expresses markers, such as cytokeratin
$5,-5 / 6,-14$ and -17 (28). Secretory carcinoma is characterized by microcystic, solid and tubular architecture and presence of vacuolated tumor cells producing intracellular and extracellular secretions. It occurs in $<1 \%$ of the patients and is referred to as juvenile carcinoma, as it is common in adolescents and often reported to have favorable outcomes. It is also characterized by ETV6-NTRK3 fusion (29-31). The rarest among all the subtypes is glycogen-rich clear cell carcinoma, in which the tumors appear in sheets and cells are polygonal in shape, with a clear cytoplasm and the presence of glycogen (32). In these sheets, there are areas of lymphocytic infiltration and plasma cells.

Among the histological subtypes, adenoid cystic carcinoma has a median recurrence of only 2 months, and metaplastic carcinoma has $\sim 9.9$ months (33), compared to IDC-NST and matrix-producing metaplastic carcinoma, which are less aggressive, with 34 and 31.4 months of median time to recurrence, respectively (20).

Although the histological assessments were pointing to the presence of WBCs in and around the TNBC subtypes, focus on the presence of WBCs has led to the identification of TILS and TAMs, which are the parameters defining prognosis and therapy of TNBC. The TNBCs might be immunogenic due to mutations that lead to aberrant protein expression on the cell membrane (34). Tumor-infiltrating lymphocytes (TILs) are white blood cells that migrate towards the tumor from the bloodstream via the newly formed blood vessels (angiogenesis), which cancer cells use for their nutritional and oxygen requirements (35). They consist of a mixture of $\mathrm{B}$ cells, macrophages, natural killer cells and are dominated by T cells (35). TILs are present in $20 \%$ of TNBC tumors and carry a pivotal prognostic and predictive value (36). The presence of TILs indicates a good prognosis (37). High number of TILs indicate that there is an equilibrium between the immune status and cancer (38). The ratio of cancer cells: TILs is tilted towards TILs after surgical removal of a tumor, resulting in an improved prognosis in TNBC (38). A high mutation load and clonal heterogeneity are associated with a low number of TILs, which may provide an escape route to tumor cells from immune surveillance (39). However, in addition to TILs, the tumor microenvironment components also influence the outcome of patients with TNBC (39). Relapsing patients with TNBC have been shown to have low levels of TILs and a high number of $\mathrm{CD} 163^{+}$tumor-associated macrophages (TAMs) compared with that of patients without relapse (39). High levels of $\mathrm{CD}^{+} \mathrm{T}$ cells may reflect improved sensitivity to chemotherapy, whereas high levels of TAMs correlate with poor patient outcomes (36). Nevertheless, a previous study in TNBC has reported paradoxical findings, with high levels of $\mathrm{CD}^{+} \mathrm{T}$ cells in the tumor stroma leading to the low infiltration of the tumor epithelium, thereby indicating a poor outcome (40). Therefore, immunohistological assessment for TILS or TAMS will help develop immunotherapies detailed in section 7 .

\section{Multiomics-guided molecular classification of TNBC}

Profiling based on gene expression has led to improved insight into tumor heterogeneity at the molecular level and has generated an impartial classification (Fig. 1). The PAM50 


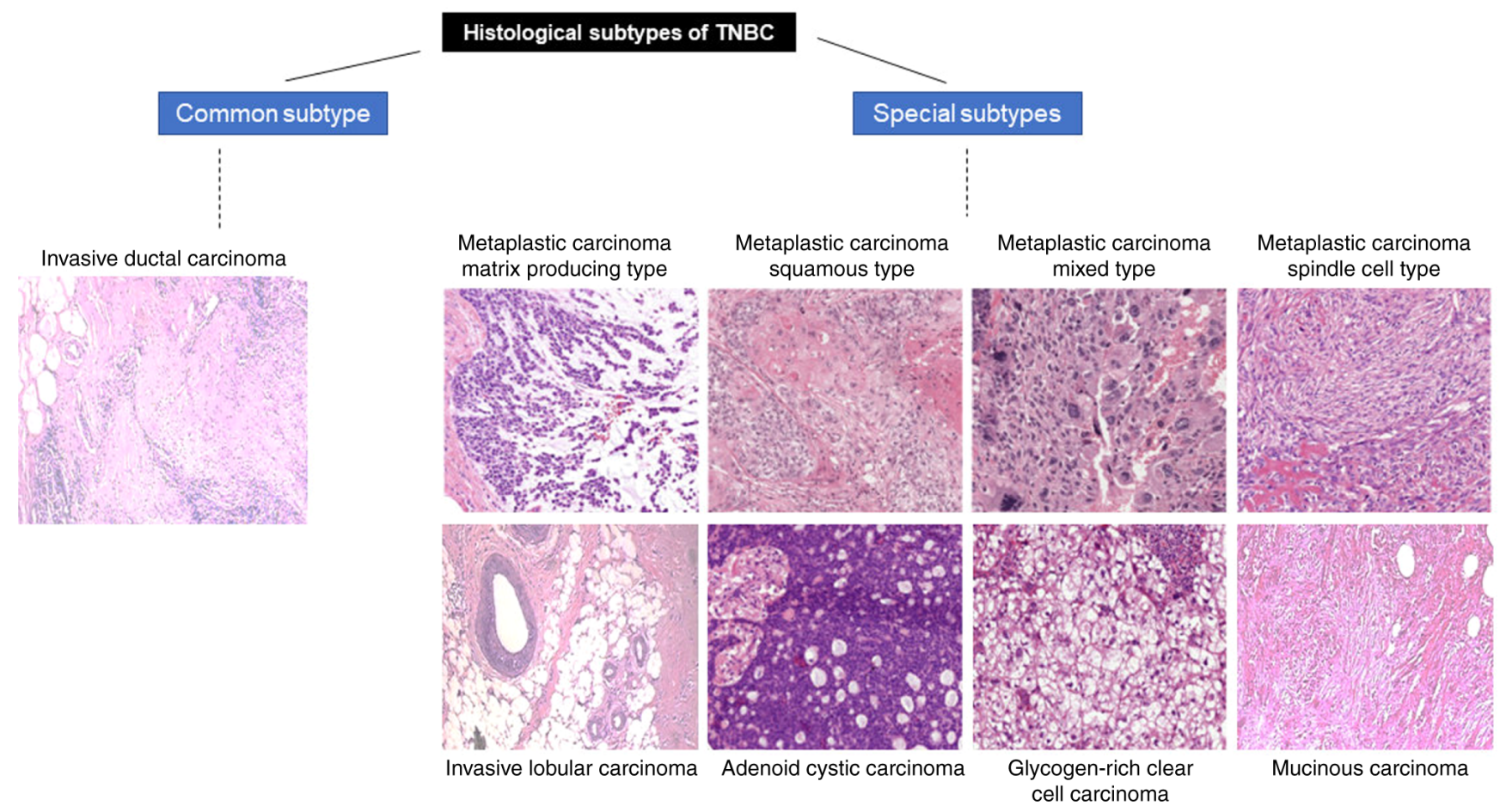

Figure 1. Histological classification of TNBC. Among the histological subtypes, invasive ductal carcinoma is the most common. Metaplastic, adenoid cystic, invasive lobular, mucinous and glycogen-rich clear cell carcinoma are rare subtypes of carcinoma. Metaplastic carcinoma can be further divided into matrix-producing, squamous, mixed and spindle-cell type, depending on the cell type (15). The permission to use this figure is licensed under a Creative Commons Attribution-ShareAlike 4.0 International License with Elsevier. TNBC, triple-negative breast cancer.

microarray set of 50 genes is used to identify breast cancer intrinsic subtypes (41). A set of 374 TNBC samples taken from 14 microarray datasets was analyzed to characterize TNBC subtypes using PAM50. The results from this analysis categorized most of the TNBC as basal-like (80.6\%). The rest of the tumours were classified as Her2-positive $(0.2 \%)$, normal-like (14.6\%), luminal B (3.5\%) and luminal A $(1.1 \%)$ (Table I) (41).

Lehmann et al (42) performed gene expression profiling of 2,188 genes from 587 patients with TNBC and classified TNBC into six new groups, namely, basal-like 1 (BL1), basal-like 2 (BL2), immunomodulatory (IM), luminal androgen receptor (LAR), mesenchymal stem cell-like (MSL) and mesenchymal (M). The rest was classified as an unstable type (UNS/UNC). Each subtype had its characteristic feature. Basal-like was the most common type of TNBC (BL1, 22\%; BL2, 12\%) and was characterized by high $\mathrm{Ki} 67$ and DNA damage response levels. The IM subtype (18\%) had basal-like characteristics with activation of IFN $\alpha$ and IFN $\gamma$ signaling and high cytotoxic T-lymphocyte associated protein 4 gene expression. Mesenchymal subtypes (M, 21\%; MSL, 10\%), along with cell differentiation pathways, showed deregulation of EGFR, calcium signaling, MAPK, and PI3K signaling. In the LAR subtype (9\%), an $\sim 10$-fold increase in androgen receptor (AR) expression was seen, compared with other subtypes. Activation of various pathways, such as steroid synthesis and FOXA1 and ERBB signaling, were observed in this subtype (Table I) $(42,43)$.

Burstein et al (43) used a non-negative matrix factorization method to derive a panel consisting of 80 core genes that divided TNBC into four subtypes, luminal-AR (LAR), mesenchymal
(MES), basal-like immune-suppressed (BLIS), and basal-like immune-activated (BLIA). BLIA has the best disease-free survival outcome compared to other subtypes (44). Based on DNA copy number, these subtypes can be placed into two groups, LAR or others (Table I) (31).

Liu et al (45) performed mRNA and long non-coding RNA (lncRNA) expression analysis in 165 TNBC tumor samples at Fudan University Shanghai Cancer Centre. The tumor samples were categorized into four subtypes (IM, LAR, MES, and BLIS subtypes), consistent with the classification by Burstein et al (43). The IM subtype comprised of genes related to immune functions such as CCR2, CXCL13, CXCL11, CD1C, CXCL10, and CCL5, along with ENST00000443397 long ncRNA. In contrast, the LAR subtype had enrichment of hormone regulation signaling and ENST00000447908 lncRNA (45). The MES subtype expressed lncRNA NR_003221 together with genes and pathways that promoted epithelial-to-mesenchymal (EMT) transition. Pathways and molecules such as DNA repair, replication, and mitosis, lncRNA TCONS_00000027 were enriched in the BLIS subtype $(45,46)$.

Genomic/transcriptomic data from a set of 997 primary tumors were extracted, and an integrated analysis was performed by Curtis et al (47). A set of 995 tumors from the Molecular Taxonomy of Breast Cancer International Consortium (METABRIC) cohort was used as a validation set that divided TNBC into ten groups, named Integrated Clusters (IntClust) 1-10 (47). Basal-like breast cancer mostly fell in IntClust 4 and $10(\sim 80 \%)$. IntClust 4 is known to have greater TIL counts, while IntClust 10 subtype can display genomic instability and chromosomal aberrations (Table I) (47-49). 


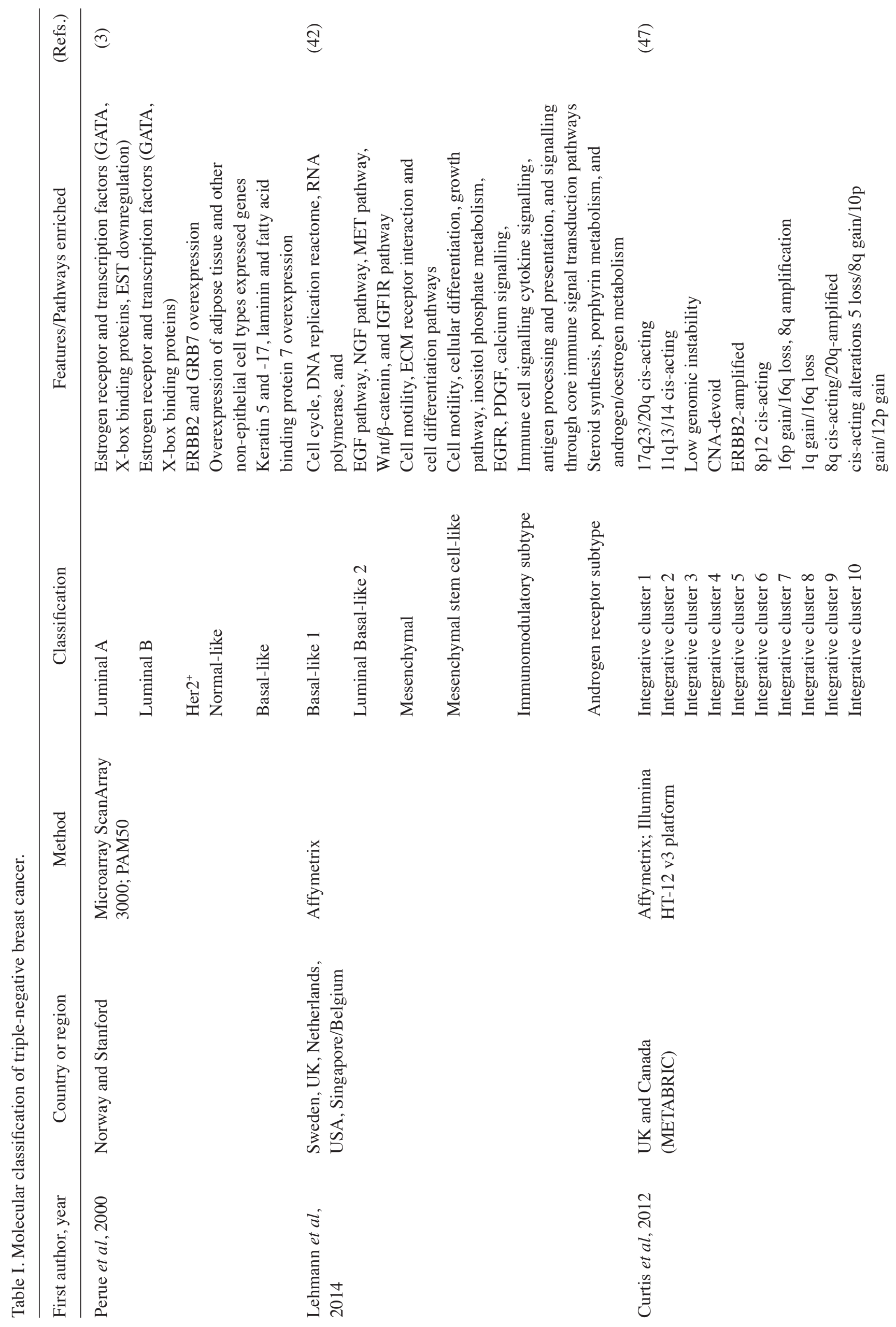




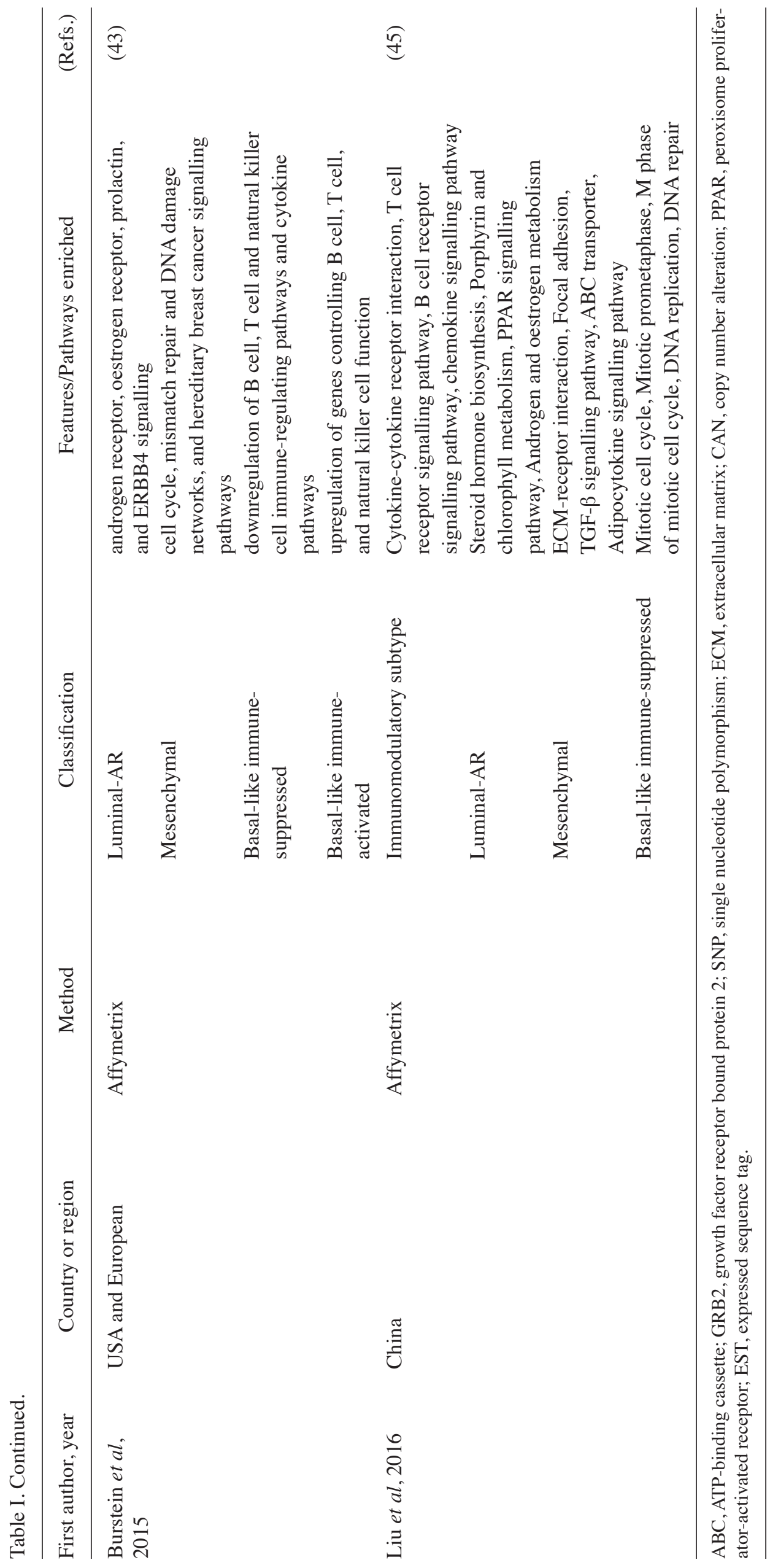




\section{Molecular aberrations in TNBC}

Through whole-exome and whole-genome data, it is evident that most of the genetic alterations in TNBC are copy number alterations and somatic mutations (40). The BRCA1 and BRCA2 tumor suppressor genes are required for the maintenance of genomic stability. These genes play a role in DNA repair and replication error control $(50,51)$. A total of $10 \%$ of patients with TNBC are known to harbor germline mutations in BRCA1 or BRCA2 $(12,26,27)$. The lifetime risk of breast cancer becomes $60-70 \%$ in the presence of such mutations (52). Gene alterations leading to homologous recombination (HR) defects other than germline BRCA mutations are termed 'BRCAness' (53). Moreover, $35 \%$ of TNBC tumors show abnormalities in the HR pathway, making them sensitive to poly (ADP-ribose) polymerase (PARP) inhibitors and DNA-damaging agents (54).

Other common mutations observed in TNBC patients include those in TP53 (50-60\%) and PIK3CA $(\sim 10 \%)(18,42)$. An analysis from the Catalogue of Somatic Mutations in Cancer (COSMIC) database revealed that the top genes mutated in TNBC, apart from BRCA1/2, TP53, and PIK3CA, were RB1, PTEN, NOTCH1 and BRAF (Fig. 2A). Among the point mutations observed, $34 \%$ of them were nonsense substitutions (where a base change leads to a stop codon in the DNA sequence), $21 \%$ were synonymous mutations (where a change in a base in the exon of a coding gene does not change the structure of the protein) (Fig. 2B). The rest of the mutations were missense mutations, frameshift insertion/deletions, and in-frame insertions/deletions. In the metastatic disease setting, genes from HR repair showed a larger frequency of biallelic loss-of-function mutations than in early TNBC (55).

Integrated analysis of The Cancer Genome Atlas (56) has demonstrated deletions in PTEN, DUSP4, and INPP48 involved in the PI3K-AKT pathway. Gene amplifications were seen in MYC, PIK3CA, KRAS, BRAF, FGFR, MET, and EGFR. Mutations in genes, such as ERBB2, AKT1, ATR, MAP3K1, CDKN2A, ATM, and NOTCH2 $(18,42,51)$, were also observed. Based on the mutation signatures obtained from whole-genome sequencing of 560 tumors, TNBC could be classified into four mutation subtypes, namely, APOBEC-based signatures, HR deficiency-based signature (signature 3), Clock-like signatures (signatures 1 and 5), and mixed (no prominent signature) $(56,57)$. These mutations suggest that DNA repair, the PI3K/AKT pathway, cell cycle checkpoints, and Notch signaling are possible druggable pathways in TNBC (58).

\section{Circulating tumor cells (CTCs) in TNBC}

Recently, much focus has been put on bringing liquid biopsies, such as circulating tumor cells (CTC) and circulating tumor DNA (ctDNA), into the clinical setting for diagnostic and prognostic use (59). CTCs are nucleated cancer cells present in the bloodstream that can be detected using techniques, such as reverse transcription-quantitative PCR, flow cytometry, and immunohistochemistry (60). Tumor cells that undergo necrosis or apoptosis release DNA fragments into the plasma are referred to as ctDNA (61). In breast cancer, ctDNA and CTCs have been studied as potential biomarkers for prognosis (60).
Stover et al (62) performed studies in metastatic breast cancer patients receiving chemotherapy and identified an association between CTCs and ctDNA and tumor burden, indicating that these could be used to measure early-treatment response in patients. A retrospective study in 164 patients with metastatic TNBC revealed that $>10 \%$ of patients with ctDNA had worse disease-free survival (62). A study by Bidard et al (63), with metastatic breast cancer, revealed that patients with CTC levels $>5$ per $7.5 \mathrm{ml}$ were associated with lower progression-free survival (PFS) and OS compared with patients who had CTC levels $<5$ per $7.5 \mathrm{ml}$. Cristofanilli et al (64) reported that CTC counts could be utilized to classify metastatic patients into two groups. Patients with CTCs levels $>5$ per $7.5 \mathrm{ml}$ were categorized as aggressive stage IV and those $<5$ per $7.5 \mathrm{ml}$ as indolent stage IV (64). ctDNA has been associated with chemotherapy in studies by Riva et al (65), in which ctDNA-positive patients before and after chemotherapy experienced poor OS and disease-free survival (DFS). Additionally, Radovich et al (66) reported that patients with early-stage TNBC and positive ctDNA after chemotherapy had a higher risk of disease relapse. Therefore, liquid biopsies are being developed as a non-invasive method to study recurrence, treatment response, and survival in the clinical setting.

\section{Conventional mode of treatment in TNBC}

TNBC treatment involves a combination of surgery, radiotherapy, and chemotherapy. New methods, such as targeted therapy and immunotherapy, have been developed to improve patient survival and prognosis. Lumpectomy and mastectomy are the surgical procedures performed for TNBC patients and are usually followed by radiotherapy and chemotherapy (67). Neoadjuvant therapy is given before the surgery, which may help shrink the tumor size and avoid mastectomy (Fig. 3) (61). Taxanes and anthracyclines form the current standard of care for TNBC in both the neoadjuvant and the adjuvant settings. Epirubicin and doxorubicin are the most common anthracyclines (anticancer antibiotics known to disrupt DNA replication and mitochondrial functions to activate apoptosis) $(68,69)$. Taxanes block angiogenesis by inhibiting epidermal growth factor receptor signaling (70).

Paclitaxel and docetaxel are familiar examples of taxanes used in the first line of therapy (71). TNBC shows a $40 \%$ pathological complete response (pCR) for taxane and anthracycline-based therapy in the neoadjuvant setting (72-74). Adjuvant therapy guidelines are usually identical for all the subtypes of breast cancer and TNBC. Chemotherapy in the adjuvant setting is recommended for tumors $>0.5 \mathrm{~cm}$ in size, as they exhibit increased aggressiveness, with a faster growth rate and metastasis (75). Anthracycline chemotherapy (cyclophosphamide and 5-fluorouracil) in patients with metastatic TNBC exhibited a response to survival within 22 months (69). However, acute toxicity is a major concern with anthracycline-based chemotherapy (76). Metastatic patients who develop resistance to anthracycline have shown sensitivity to capecitabine, gemcitabine and vinorelbine (77-79). The combination of docetaxel with capecitabine has improved the OS of patients with metastatic TNBC (78).

Carboplatin and cisplatin are platinum salts that are used in the treatment of TNBC. These generate DNA lesions, and 

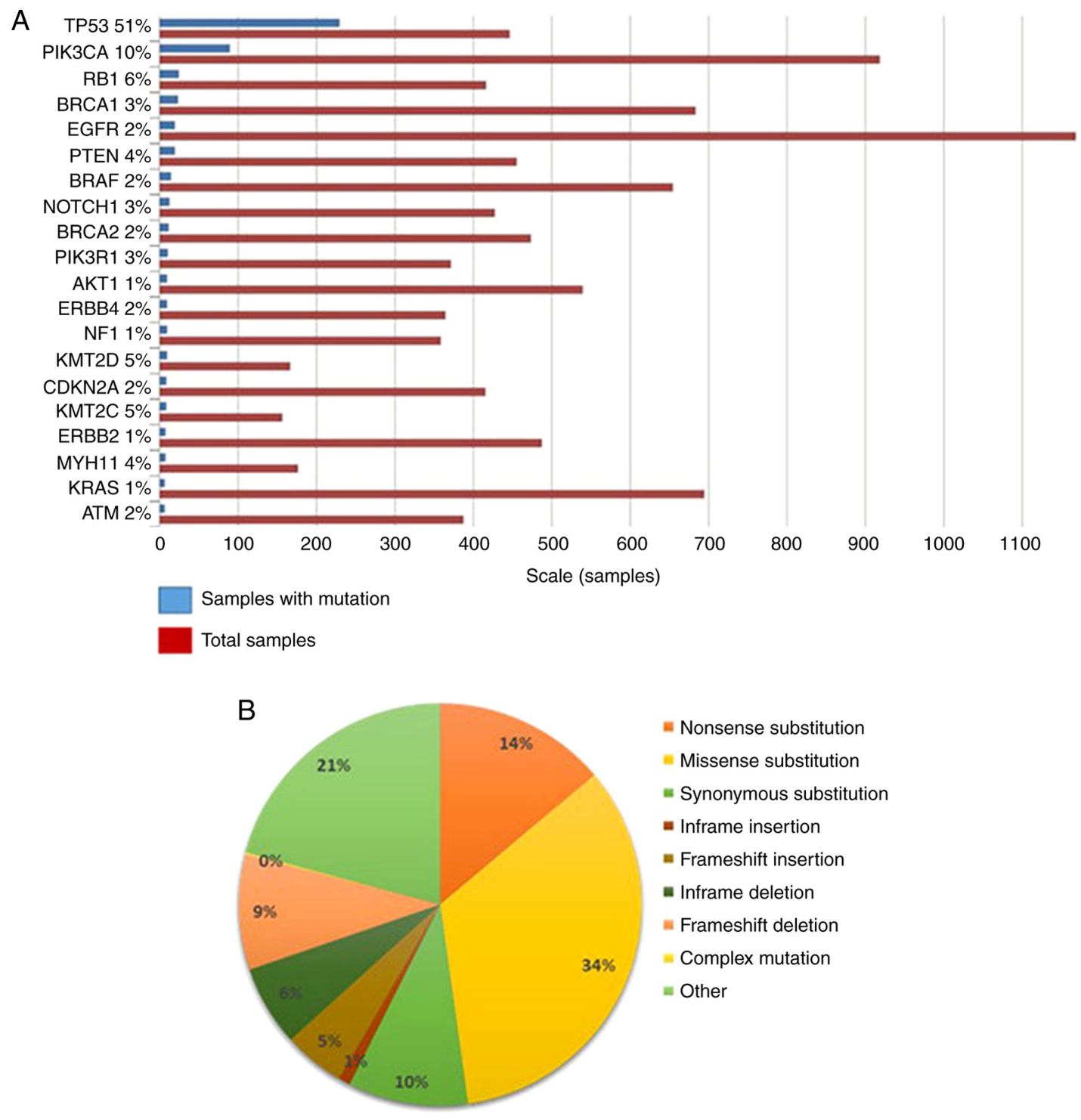

Figure 2. Mutation status of the top 20 genes in triple-negative breast cancer identified in the Catalogue Of Somatic Mutations In Cancer. (A) Bar graph showing the number of samples harbouring mutations in the top 20 genes with most mutations. The blue bar indicates samples with mutations, whereas the red bar indicates the total number of samples. The percentage of occurrence of mutation is also shown. TP53, PI3K, BRCA1 are among the top genes in the panel with a high number of mutations. (B) Pie chart classifying the type of mutations observed in all genes. Most of the mutations fall under nonsense and synonymous type. Other mutation types, such as frameshift and in-frame mutations, were also observed.

apoptosis occurs in cells unable to repair these breaks (80). For TNBC, carboplatin as a neoadjuvant addition increases the response rate from 37 to $52.1 \%$ (81). A phase-II study of 86 patients evaluating the efficacy of platinum monotherapy demonstrated a $32 \%$ overall response rate (ORR) for cisplatin and $19 \%$ for carboplatin in early TNBC. Patients with BRCA1/2 mutations showed an improved response compared with patients without BRCA1/2 mutations (82). Moreover, phase-II trials showed an improved ORR of $72 \%$ in metastatic patients with BRCA mutation with neoadjuvant cisplatin monotherapy $(83,84)$. Recently, the PEARLY trial (NCT02441933) has explored combination therapy of taxanes and carboplatin in the neoadjuvant setting (85). Carboplatin with docetaxel or paclitaxel combination has demonstrated promising efficacy in patients with TNBC and brain metastasis (86). Although TNBC is sensitive to chemotherapy, early relapse is a major concern (75). Therefore, optimizing a tailored standard regime to address chemotherapy issues, such as toxicity, and relapse has led to customizing personalized therapy based on tumor type.

\section{Emerging role of targeted therapy as a strategy to treat TNBC}

Therapies targeted to TNBC are being developed based on the expression of specific pathways and genes. Targeted therapy focuses on customizing cancer therapy to an individual patient's tumor $(87,88)$. TNBC being heterogenous, targeting alterations specific to the tumor would be the most effective treatment option. A study using genomics and transcriptomics has led to identifying molecular markers that could be effectively targeted in TNBC (89). PARP inhibitors, PI3K/AKT inhibitors, and anti-androgen therapy are under clinical investigation (Fig. 3) (58). 


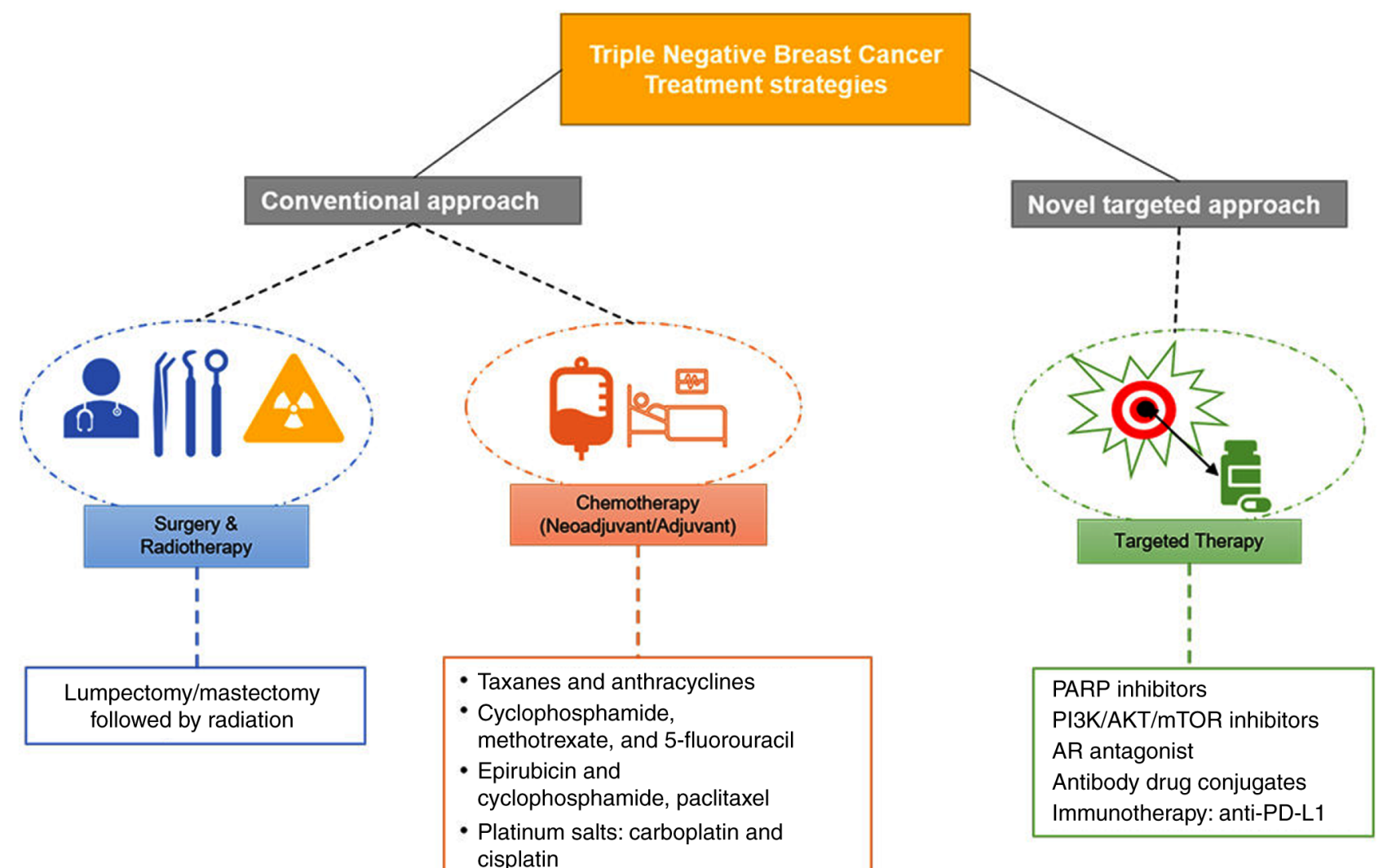

Figure 3. Different modes of treatment employed in TNBC therapy. The traditional method of treating cancer (surgery and radiotherapy) is still the primary mode of initial treatment followed by chemotherapy. Taxanes and anthracyclines are common chemotherapeutic agents used for the treatment of TNBC along with platinum salts. Recently, due to the development of omics technology, targeted therapy has become a novel way of treating cancer. AR, androgen receptor; PARP, poly (ADP-ribose) polymerase; PD-L1, programmed death ligand 1; TNBC, triple-negative breast cancer.

PARP inhibitors for patients with a BRCA1/2 mutation. PARP is expressed in ample amounts as a nuclear enzyme that plays a critical role in DNA repair, cell proliferation, and signaling. It transfers ADP-ribose to target proteins from $\mathrm{NAD}^{+}$and ribosylates them (90). In response to DNA damage, PARP is known to activate the DNA repair process through poly (ADP)-ribosylation of multiple nuclear proteins that play a role in chromatin architecture and DNA metabolism (91). Therefore, PARP inhibition leads to the accumulation of double-strand breaks (DSBs) in cells undergoing replication. The presence of wild-type BRCA1/2 in cells results in a homologous recombination mode of repair of DSBs. However, in the cells deficient of BRCA1/2, homologous recombination is disrupted, and PARP repairs the breaks (92-94). Therefore, in these BRCA1/2-deficient cases, inhibiting PARP will result in severe, selective toxicity called 'synthetic lethality' (95). Using PARP inhibitors in treatment sensitizes the tumor cells to chemotherapy and radiotherapy, causing synthetic lethality in patients with hereditary BRCA1/2 mutations identified in several TNBC subtypes (Fig. 4A) (96).

Olaparib and talazoparib are two of the PARP inhibitors approved by the United States Food and Drug Administration (FDA) for use in patients with deficient BRCA1/2 in metastatic Her2-negative breast cancer as a single agent, based on the phase-III OlympiAD and EMBRACA clinical trials (86-88). Patients with a germline BRCA1/2 mutation (gBRCA1/2+) with metastatic breast cancer were grouped into 2:1 to olaparib vs. chemotherapy (capecitabine, eribulin, or vinorelbine) of physician's choice in OlympiAD trial (NCT02000622) $(97,98)$. The ORR was $59.9 \%$ in the TNBC patient subgroup for olaparib $(n=102)$ and $29.9 \%$ in the case of patients who underwent chemotherapy $(n=48)$. Olaparib showed less toxicity in tumorgrade 3 and 4 patients than the chemotherapy arm $(98,99)$. In the EMBARCA trial (NCT01945775), gBRCA1/2+ metastatic patients were given 2:1 Talazoparib $1 \mathrm{mg}$ daily vs. chemotherapy of physician's choice. The ORR was $62.6 \%$ in patients given with Talazoparib $(n=219)$ and $27.2 \%$ in patients treated with chemotherapy ( $n=144)$ (99). Several other PARP inhibitors are currently under phase-II/III clinical trials, including veliparib (NCT02163694) and niraparib (NCT01905592) (100-103).

PARP inhibitors are being investigated in combination with chemotherapy and immunotherapy. BrighTNess trial (NCT02032277) is a phase-III trial for stage-II and -III TNBC evaluating the combination of carboplatin with the PARP inhibitor veliparib followed by doxorubicin (104). The ongoing phase-I/II trial (MEDIOLA trial) involves a combination of olaparib and anti-PDL1 checkpoint inhibitor durvalumab (105). The phase-III OlympiA trial (NCT02032823) for early TNBC is currently assessing patients with BRCA1/2 mutation treated with olaparib as monotherapy following neoadjuvant chemotherapy (106). PARTNER (NCT03150576) (107) is a phase-II/III trial that is currently ongoing checking the efficacy of olaparib and carboplatin combination in a neoadjuvant setting (107). Table II summarizes the clinical trials taken from clinicaltrials.gov. 
A

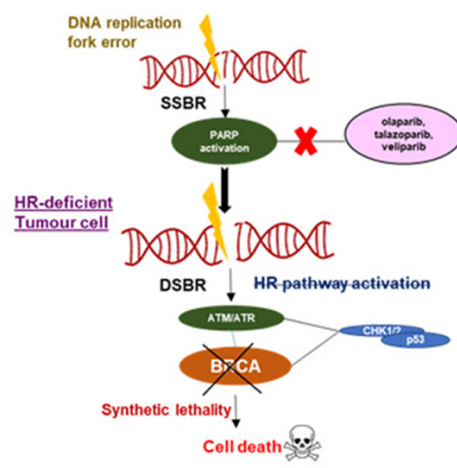

B

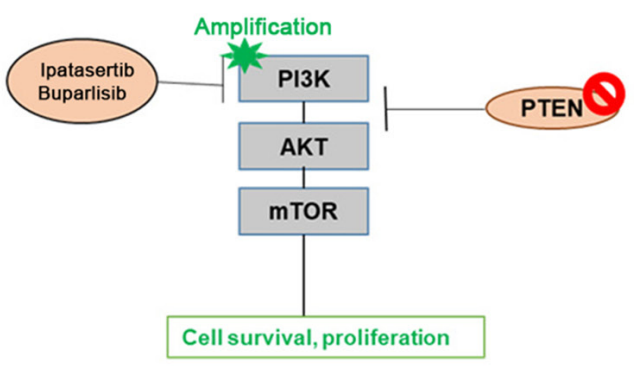

C

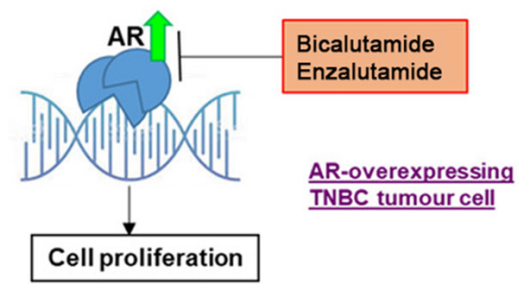

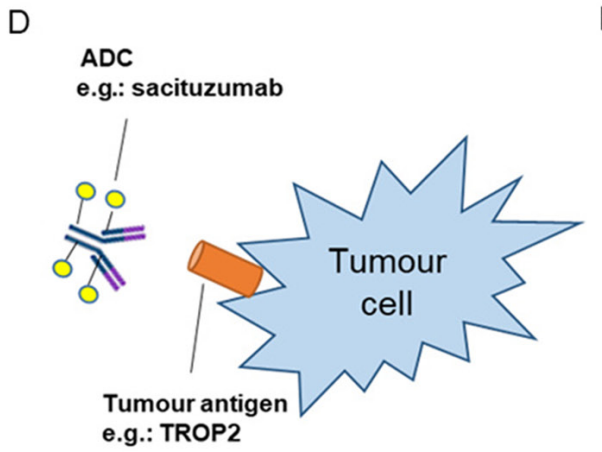

$\mathrm{E}$

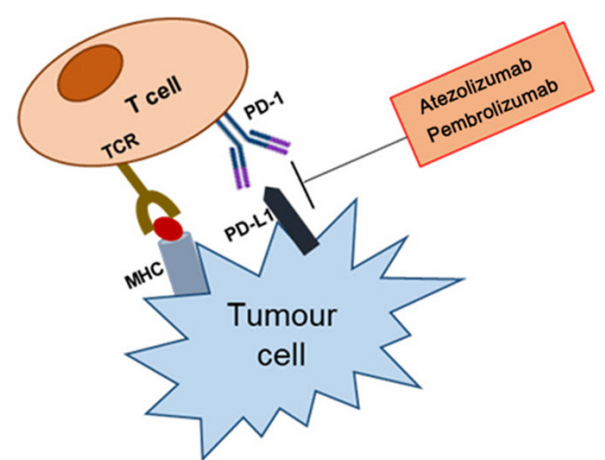

Figure 4. Targeted therapies currently explored for TNBC. (A) PARP inhibitors, such as olaparib and veliparib are currently under clinical trials to bring about synthetic lethality in homologous recombination-deficient TNBC harbouring BRCA1 mutations. (B) PI3K-activated TNBC with loss of PTEN can be treated with buparlisib or ipatasertib, which inhibit the PI3K enzyme. (C) In the LAR subtype of cancers, where the expression of AR is very high, AR blockers like bicalutamide and enzalutamide have made their way. (D) Antibody-drug conjugates are specific to cell-surface molecules and linked to a potent cytotoxic agent that kills the cancer cell. (E) PD-L1 blockade using atezolizumab has shown positive results in a clinical trial on patients with TNBC. AR, androgen receptor; DSBR, double-strand break; MHC, major histocompatibility complex; PARP, poly (ADP-ribose) polymerase; PD-1, programmed death-1; PD-L1, PD ligand 1; SSBR, single-strand break; TCR, T cell receptor; TNBC, triple-negative breast cancer; LAR, luminal androgen receptor; ATM, ataxia telangiectasia mutated; ATR, ataxia telangiectasia and rad3-related protein; HR, homologous recombination; ADC, antibody-drug conjugates; TROP-2, tumour associated calcium signal transducer 2 .

PI3K/AKT inhibitors for PTEN low TNBC. PI3K/AKT pathway is involved in cell growth and glucose metabolism. Under normal conditions, growth factors, such as insulin-activated receptor tyrosine kinases (RTKs) result in PI3K activation (108). This is followed by phosphorylation of phosphatidylinositol-4,5-trisphosphate (PIP2) by PI3K and conversion to phosphatidylinositol-3,4,5-trisphosphate (PIP3) (109). AKT binds to membrane-bound PIP3, bringing AKT close to phosphoinositide-dependent kinase 1 (PDK1) (110). PDK1 phosphorylates AKT resulting in the activation of multiple downstream pathways like cell growth, cell cycle, and metabolic pathways. This pathway is negatively regulated by the PTEN phosphatase $(108,109,111)$. In TNBC, this pathway is active in $9.6 \%$ of patients due to the loss of PTEN activity (110) (Fig. 4B). Therefore, studies using PI3K inhibitors have been conducted in patients with TNBC (Table II), such as the LOTUS trial (NCT02162719), which is a phase-II trial evaluating ipatasertib in 124 patients (ORR in the PTEN $^{\text {low }}$ group was $48 \%$ compared with patients with PTEN expression) (112). The oral pan-PI3K inhibitor buparlisib has also been used in combination with paclitaxel in a phase-II trial (NCT01572727) involving metastatic Her2-negative patients; the ORR was $22.6 \%$ compared with placebo and paclitaxel (113).

Capivasertib and AZD5363 are AKT inhibitors that are currently being investigated for PFS in patients with metastatic TNBC in the CAPItello-290 (NCT03997123) and PAKT (NCT02423603) trials, respectively $(114,115)$. In the Phase-II trial under neoadjuvant setting, mTOR inhibitor and chemotherapy combined did not show any effect in early TNBC treatment (116). The mTOR inhibitors temsirolimus or everolimus in combination with doxorubicin and bevacizumab displayed an objective response rate of $21 \%$ in mesenchymal subtype of TNBC (117).

AR inhibitors for AR-overexpressing TNBC. AR belongs to the nuclear steroid hormone family of receptors, is highly expressed in the LAR subtype of TNBC (118). AR antagonists have shown an effect in vitro and in vivo in the LAR type (Fig. 4C). Gucalp et al (119) used the AR inhibitor bicalutamide in a phase-II trial involving 424 AR-positive patients, which showed a clinical benefit rate of $19 \%$ and a median progression-free survival of 12 weeks (119). Among the ongoing clinical trials, Bicalutamide treatment response is being compared to standard chemotherapy in patients with metastatic TNBC in an ongoing phase-III as the first line of therapy (NCT03055312). Enzalutamide is another AR antagonist with which a phase-II trial (NCT01889238) was conducted in AR-positive patients with advanced TNBC, in which a clinical benefit of $25 \%$ was observed (120). Androgen-driven gene expression signature (Dx-signature) stratified patients into a Dx-positive and a Dx-negative group. 


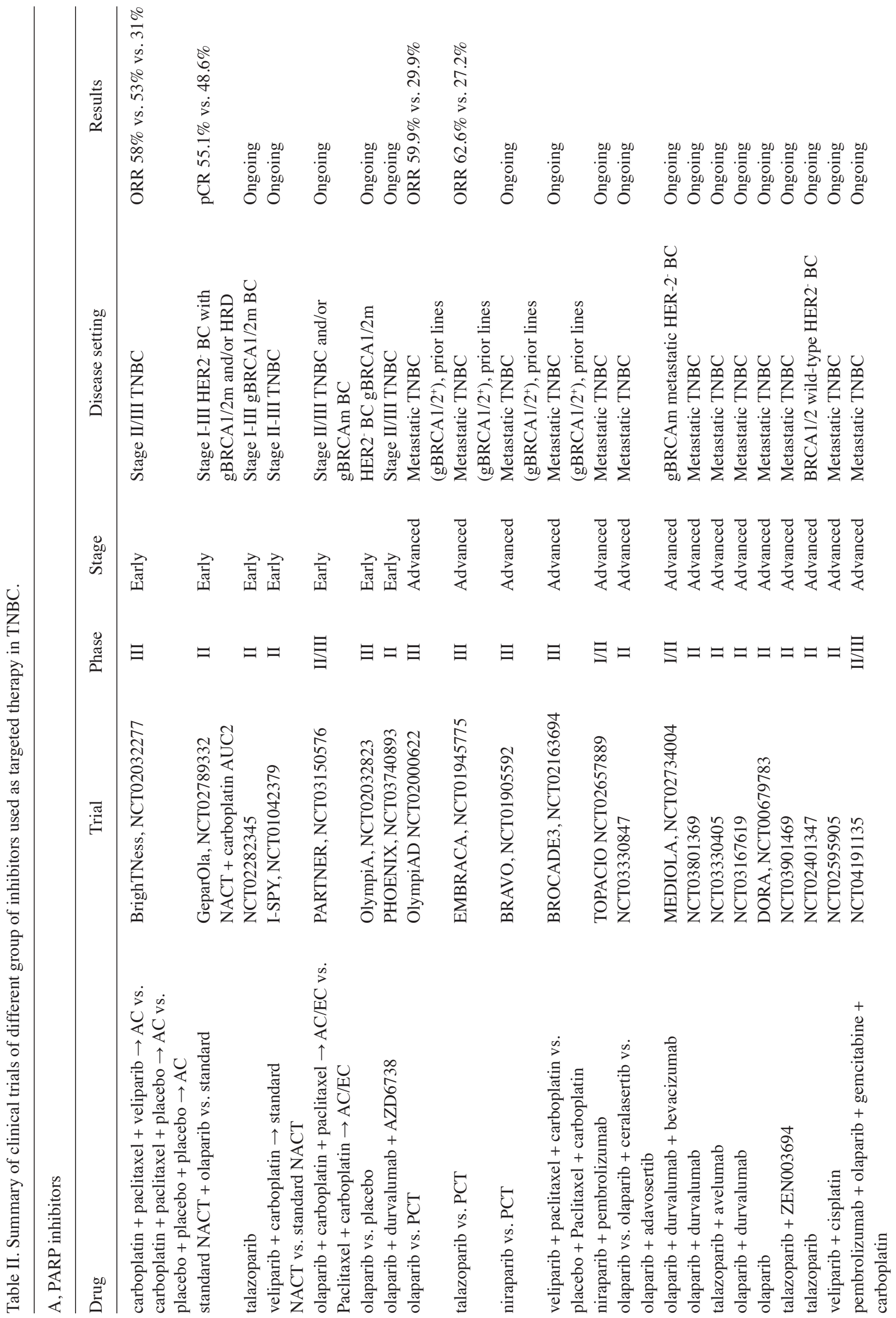



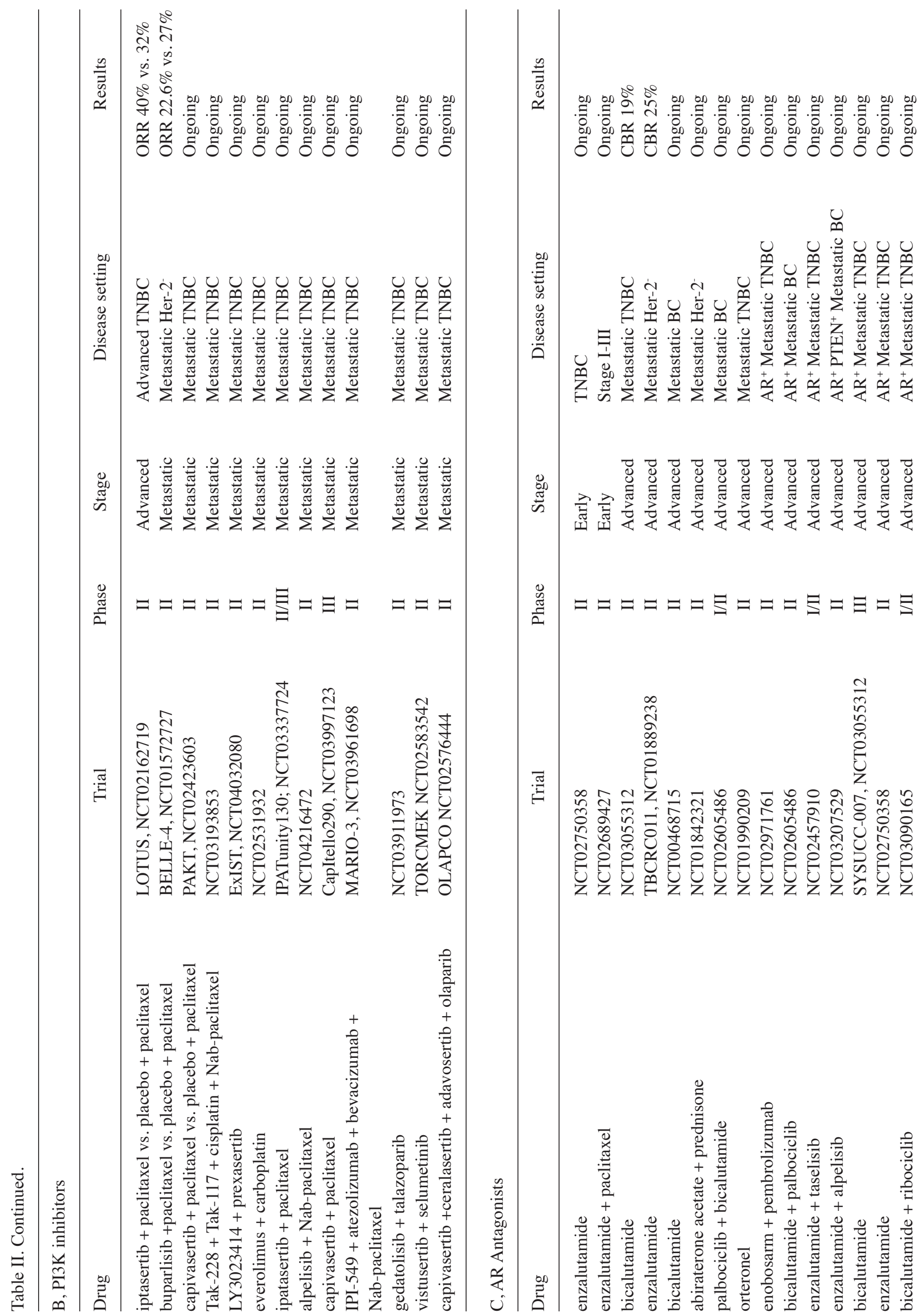

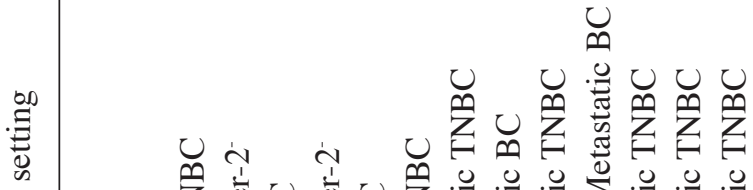

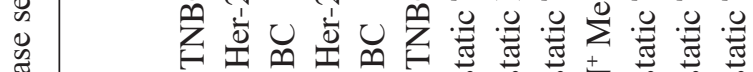

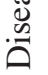

U

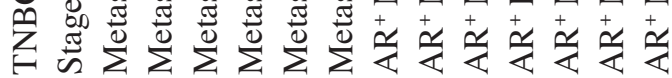

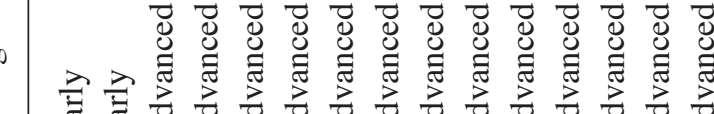

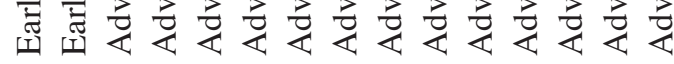

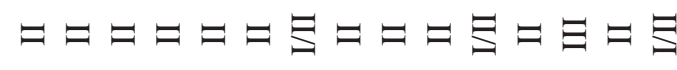

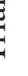

$\infty \pi \mathrm{t}$ 它

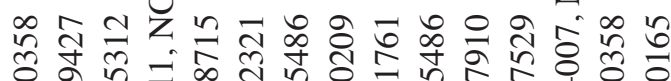

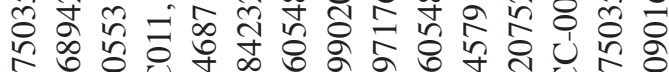

तิธิ

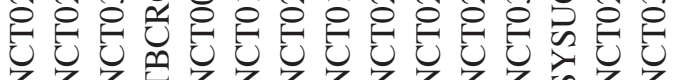

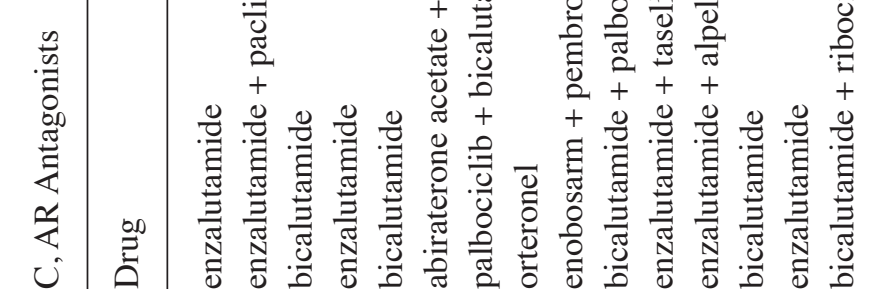




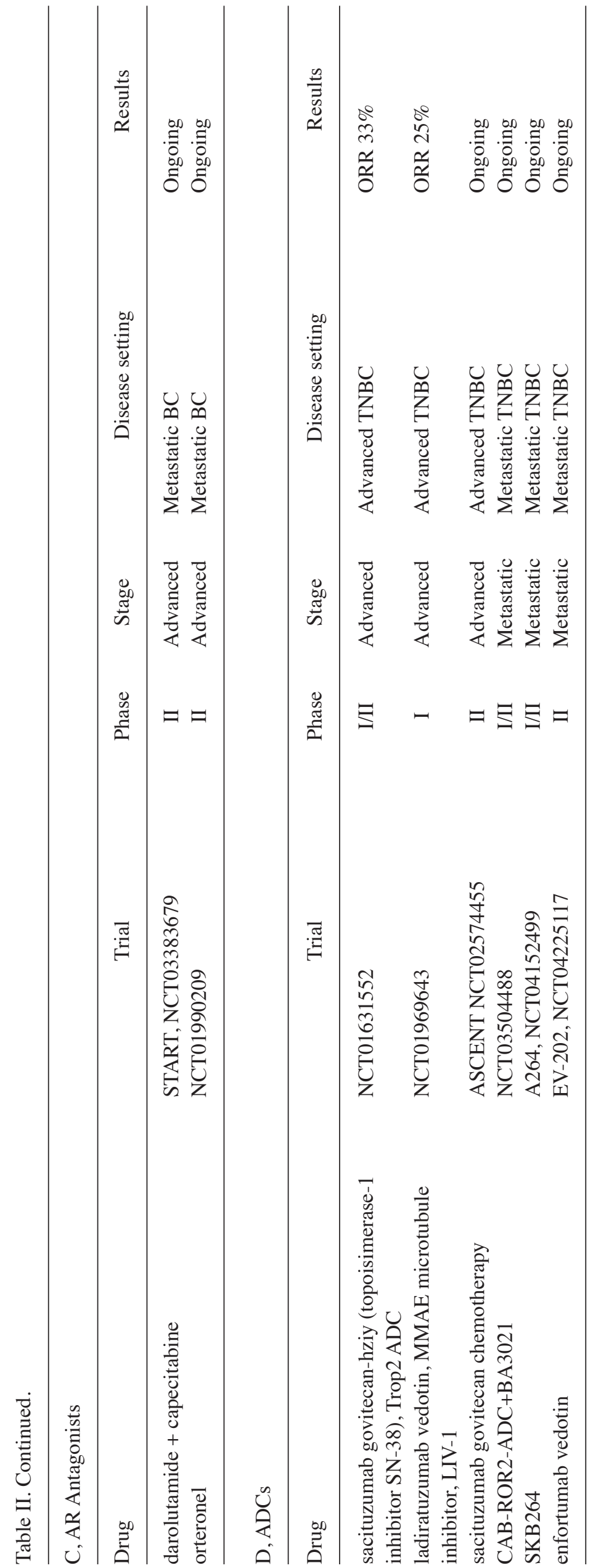

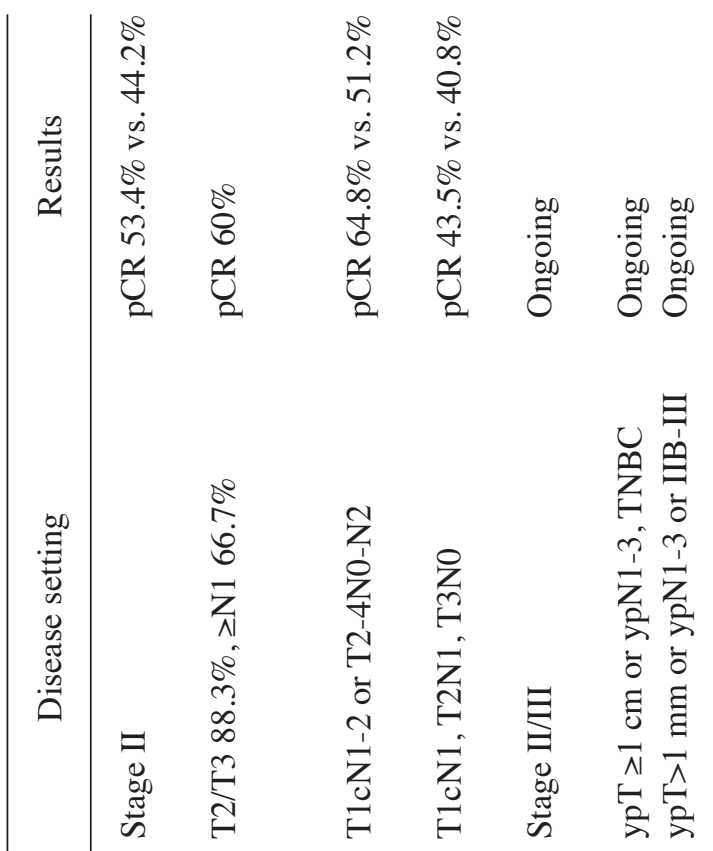

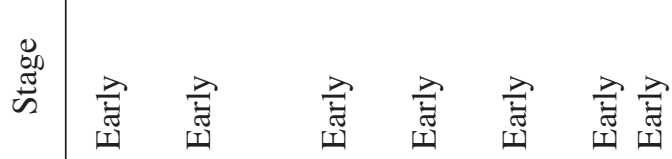

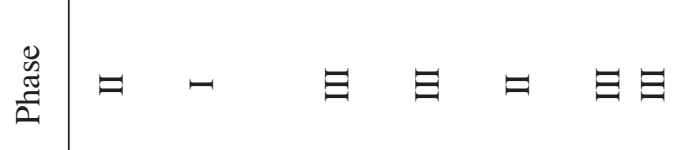

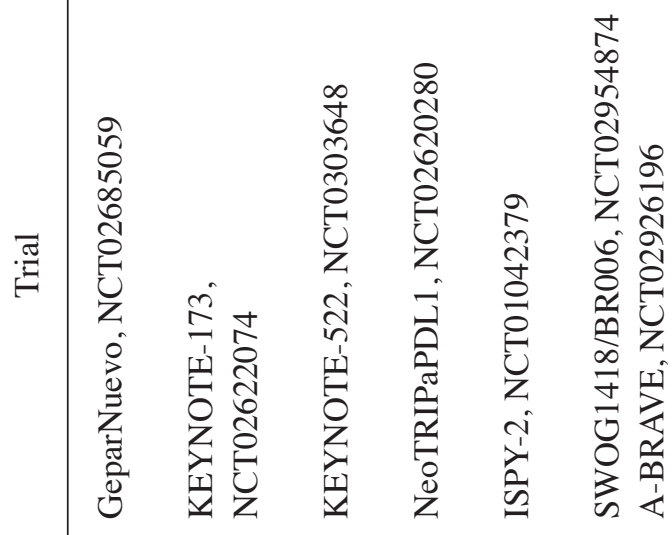

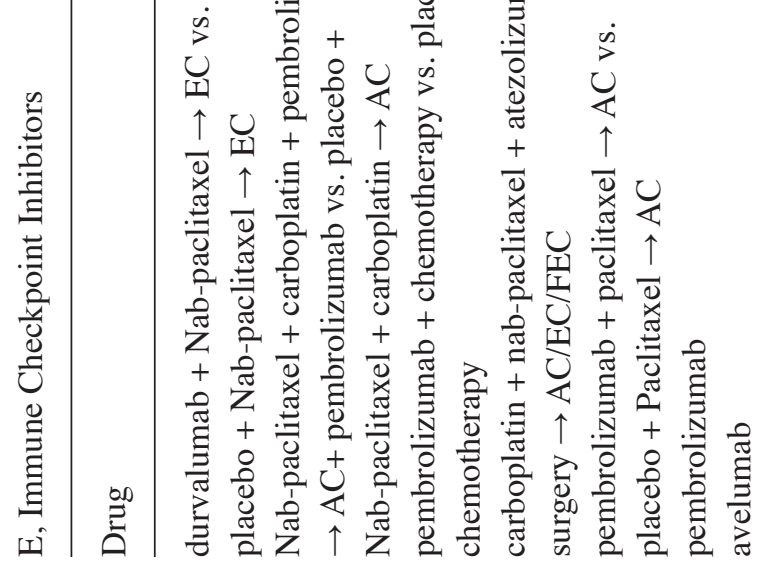




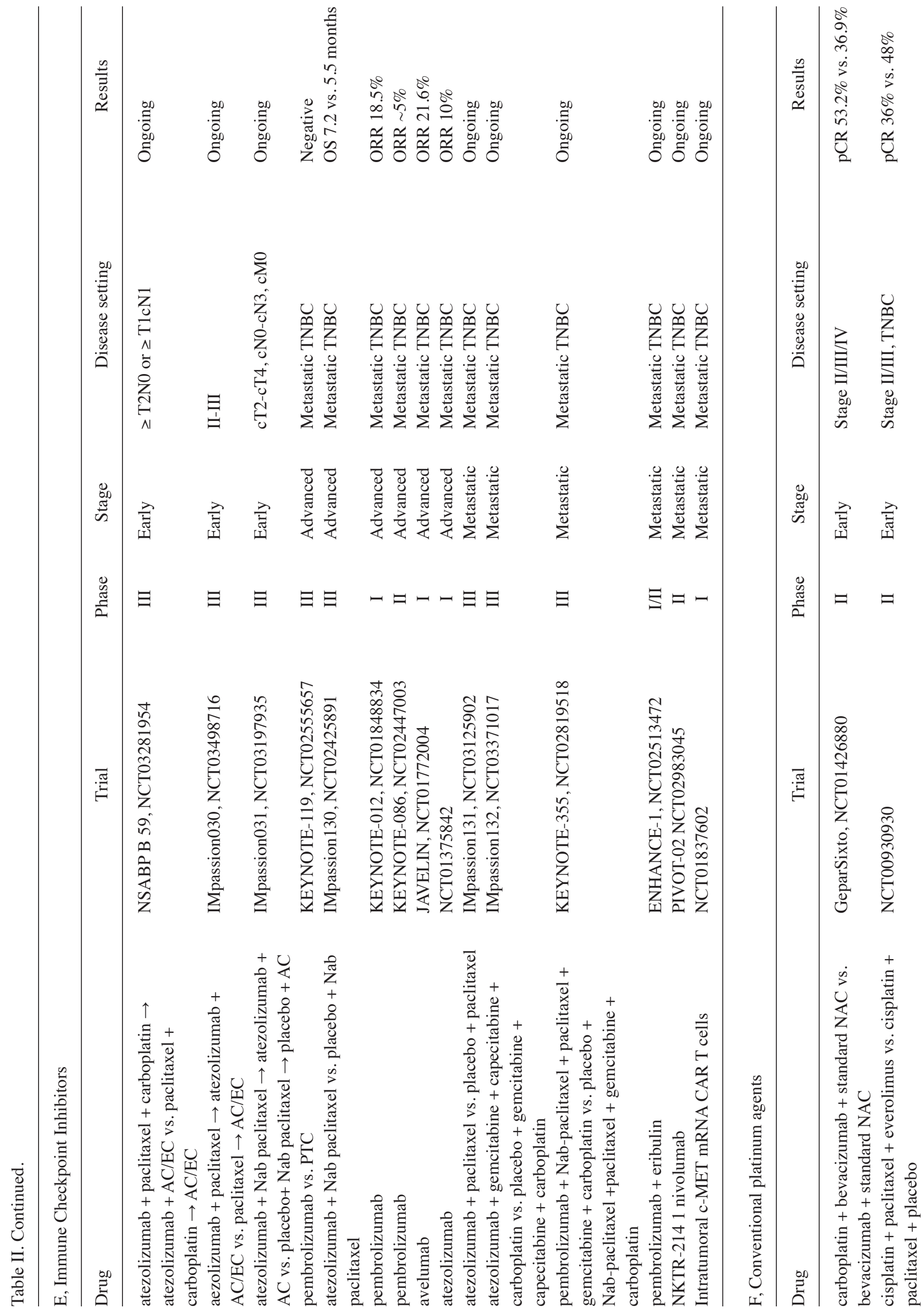


Dx-positive patients had an improved response to enzalutamide compared with Dx-negative patients $(120,121)$. In AR-positive patients with early-stage TNBC, enzalutamide is currently under investigation both as a monotherapy (NCT02750358) and in combination with paclitaxel (NCT02689427). Around 40\% of AR-positive TNBC patients show activation of the PI3K-AKT pathway (122). Therefore, the combined effect of enzalutamide and the PI3K inhibitor taselisib was evaluated in the TBRC032 trial(NCT02457910) where CBR was $35.7 \%$ (123). Further details are provided in Table II.

Antibody-drug conjugates targeting surface antigens. Antibody-drug conjugates (ADC) are made up of a linker, an inhibitor, and an antibody. The antibody is selected to be specific to cell surface molecules of cancer cells and not normal cells. The payload of cytotoxic agents must be potent to kill the cancer cell. Usually, a stable molecule is used as a linker that will bind strongly to the inhibitor $(124,125)$ (Fig. 4D). Elevated expression of tumor-associated calcium-linked signal-transducer two cell surface glycoprotein (Trop-2) has been reported in TNBC and often correlated with poor prognosis (126). Sacituzumab Govitecan (IMMU-132) is an ADC used to target Trop-2 that delivers a topoisomerase-I inhibiting payload resulting in DSBs. Bardia et al (127) conducted a phase-I/II study involving patients with advanced-stage TNBC who had previously received two lines of treatment, and the ORR was $33.33 \%$. A phase-III study (NCT02574455) of sacituzumab govitecan in relapsed patients with TNBC is ongoing.SKB264 is another anti-Trop2 currently under investigation in the NCT04152499 phase-I trial with metastatic TNBC patients (128). Another ADC, ladiratuzumab vedotin, an immunoglobulin G1 antibody with a microtubule inhibitor (MMAE), has shown an ORR of $25 \%$ of patients with TNBC (129).

Inhibitors targeting other signaling pathways. In addition to PARP and PI3K inhibitors, inhibitors of other molecular targets are being investigated in TNBC. HDAC inhibitors are currently being investigated as monotherapy (NCT02623751) and in combination with cisplatin (NCT02393794). Various Ataxia Telangiectasia and Rad3-Related Protein (ATR) and Wee inhibitors are also in clinical trials for TNBC (1). MEK inhibitors and inhibitors of cell cycle-regulating agents, such as Aurora kinase, showed antitumor effects in animal xenografts $(130,131)$. Palbociclib, a cyclin-dependent kinase 4/6 inhibitor, was used in a phase-I study along with paclitaxel in patients with metastatic TNBC $(n=9)$. Clinical benefit was experienced in one-third of the patients (132). BCL2 inhibitors in TNBC cell lines have shown to decrease cell proliferation (133). In TNBC cells, BCL2 expression is high (134). Therefore, BCL2 inhibitors should be further investigated for their impact as monotherapy and in combination.

Immunotherapy as monotherapy and combination therapy for $T N B C$. In the last decade, substantial evidence has been generated describing the immune system's role in guiding the disease progression of TNBC (135). It is one of the rapidly progressing areas of breast cancer research. The $\mathrm{T}$ cell receptor (TCR) recognizes antigen presented on major histocompatibility complex molecules by cancer cells (136). 
Table III. Role of miRNA and lncRNA expressed in triple negative breast cancer.

A, miRNA

\begin{tabular}{|c|c|c|c|}
\hline First author, year & Names & Role in TNBC & (Refs.) \\
\hline Gorur et al, 2021; Pang et al, 2018; & miR-22 and miR-200 family & Epithelial-to-mesenchymal transition & $(159,160)$ \\
\hline Lyng et al, 2012 & $\begin{array}{l}\text { miR-190a, miR-136-5p, } \\
\text { miR-126-5p, miR-135b-5p, } \\
\text { miR-182-5p }\end{array}$ & Tumorigenesis & $(158)$ \\
\hline Huang et al, 2013; Tormo et al, 2019 & $\begin{array}{l}\operatorname{miR}-95, \operatorname{miR}-449 \text {, and } \\
\operatorname{miR} 15 a / 16\end{array}$ & Drug resistance & $(161,162)$ \\
\hline \multicolumn{4}{|l|}{$\mathrm{B}, \operatorname{lncRNA}$} \\
\hline First author, year & Names & Role in TNBC & (Refs.) \\
\hline Lin et al, 2016 & LINKA & Glycolysis and tumorigenesis & $(170)$ \\
\hline Jiang et al, 2018; Ke et al, 2016 & NEAT1 & Migration, invasion and apoptosis & $(172,173)$ \\
\hline Yang et al, 2019 & POU3F3 & Inhibits apoptosis & $(171)$ \\
\hline Sha et al, 2017 & DANCR & Inhibits apoptosis & $(177)$ \\
\hline
\end{tabular}

miR/miRNA, microRNA; TNBC, triple-negative breast cancer; LINKA, long intergenic non-coding RNA for kinase activation; NEAT1, nuclear paraspeckle assembly transcript 1; POU3F3, POU domain class 3 transcription factor 3; differentiation antagonizing non-protein coding RNA; DANCR, differentiation antagonizing nonprotein coding RNA.

It is followed by signaling from co-stimulatory factors such as CD28, modulated by immune-checkpoint (co-inhibitory) molecules (137). In TNBC, programmed death-ligand 1 (PD-L1) functions as a critical mediator of the balance and escape stages of cancer immunoediting (138-140). Around $20 \%$ of TNBC tumors express PD-L1, which is associated with poor prognostic features, such as higher grade, HER2-positive status, ER-negative status and large tumor size (141). Quantification of PD-L1 can be carried out on immune cells or tumor cells using immunohistochemistry (141-143). Studies have suggested that PD-L1 expression varies depending on the stage of TNBC and cell type (141-143). Expression of PD-L1 in TNBC has been associated with improved pCR $(50 \%$ vs. $21 \%)(39,144)$. Along with PD-L1, TILs are also high in number in TNBC $(144,145)$. TILs are considered to be a good prognostic marker in TNBC (146). Inhibitors of PD-1/PD-L1 block the interaction between PD-1 and PD-L1, thereby initiating a positive immune response that results in tumor killing (123). Over the last few years, immune checkpoint inhibitors (CPIs) have been in the limelight due to improved efficacy shown during clinical trials (Fig. 4E). Pembrolizumab (NCT04191135 and NCT01042379), nivolumab (NCT03818685 and NCT03414684), atezolizumab (NCT03281954 and NCT03498716) and durvalumab (NCT03167619 and NCT03616886) are some of the CPIs currently used in ongoing clinical trials for TNBC (147). The IMpassion130 trial (NCT02425891) evaluated the use of atezolizumab with paclitaxel as the first line of therapy for patients with metastatic TNBC $(n=901)$, showing PD-L1 positivity. Atezolizumab is a PD-LA inhibitor that blocks the interaction between PD-L1 and PD-1, thereby promoting T cell activity. It is now an FDA-approved drug for PD-L1-positive patients with TNBC (148). The KEYNOTE-119 phase-III clinical trial (149) evaluated pembrolizumab's effect as monotherapy in patients with metastatic TNBC vs. physician's choice chemotherapy (capecitabine, vinorelbine, gemcitabine, or eribulin). The OS of this study was not encouraging (149). In the recent trial KEYNOTE-355 (NCT02819518), PD-L1-positive patients with metastatic TNBC showed improved PFS when pembrolizumab was given in combination with chemotherapy, in comparison with patients given chemotherapy alone (150). Currently, two trials, IMpassion 131 (NCT03125902) and IMpassion132 (NCT03371017), are being carried out: The former is investigating the outcomes for paclitaxel and atezolizumab in untreated metastatic patients who are PD-L1 positive, while the latter is for atezolizumab along with chemotherapy (gemcitabine, capecitabine and carboplatin) in early relapsing recurrent patients with TNBC (PD-L1 positive). For early-stage breast cancer, the KEYNOTE-173 phase-Ib trial evaluated pembrolizumab along with taxane and anthracycline neoadjuvant therapy, which resulted in an ORR of $100 \%$ (151). The ISPY-2 trial was a phase-III trial evaluating pembrolizumab in combination with chemotherapy (vs. placebo) in patients with stage-II/III TNBC, which demonstrated an ORR of 60 and 20\%, respectively (152). The SWOG S1418 (NCT02954874) trial is investigating anti-PD-1/-PD-L1 in the adjuvant setting for a year in order to determine whether there is an improvement in DFS. The NSABP B-59 (NCT03281954) and IMpassion030 (NCT03498716) trials are addressing whether the combination of neoadjuvant/adjuvant chemotherapy and atezolizumab might improve DFS compared with chemotherapy alone (153). 


\section{Non-coding RNA as therapy}

Sequencing of all the RNA species in a given cell using RNA-seq identified several RNA species, including mRNA. The two major classes of non-coding RNA studied in TNBC development and treatment are miRNA and Long non-coding RNA.

MicroRNA (miRNA/miR) is a small non-coding RNA, usually 20-22 nucleotides in length, regulating gene expression. miRNA is known to bind to the 3'untranslated region of mRNA. This binding either degrades mRNA or represses translation (154). miRNA is a key player in tumorigenesis, stemness, and drug resistance in TNBC (155-157). For instance, tumour suppressor miRNAs, involved in tumour development, miR-190a, miR-136-5p, miR-126-5p, miR-135b-5p and miR-182-5p are downregulated in TNBC (158). miR-22 is downregulation in TNBC, is associated with migration and metastasis. miR-22 exerts its effect through eukaryotic elongation factor 2 kinase (eEF2K) expression, which activates PI3K signaling pathway (159). Also, oncosuppressor, miR-200b, activate target genes like SRY-box transcription factor 2 (SOX2), CD133, and zinc finger E-box binding homeobox 1 (ZEB1), aiding in migration and invasion and stemness $(157,160)$. High expression of miR-95 in TNBC indicates radiotherapy resistance that occurs by targeting sphingosine-1-phosphate signaling (161). Downregulated miR-449 upregulates CDK2, CCNE2 causing doxorubicin resistancein TNBC $(162,163)$ (Table III). Multiple studies also show that miRNAs are expressed in different stages of TNBC Multiple studies also show that miRNAs are expressed in different stages of TNBC (164-166). These studies give hope for miRNA-based therapies, as the use of miRNA mimics or inhibitor oligonucleotides could serve as a therapeutic approach for TNBC (167). A study conducted by Shu et al (168) used miR-21 combined with aptamer targeting EGFR, blocking tumor growth in murine models. Yin et al (169) designed an RNA aptamer bound to CD133 with a sequence complementary to miR-21 carried by a three-way junction motif scaffold that reduced cell migration in TNBC cells (169). Non-coding RNA is being pursued as one of the TNBC therapy.

lncRNA (long non-coding RNA), 200 nucleotides in length, regulates gene expression at the epigenetic, transcription, post-transcription levels, and post-translation modification (16). The long intergenic non-coding RNA for kinase activation activates HIF- $1 \alpha$ by phosphorylating it via leucine-rich repeat kinase 2to promote glycolysis and tumorigenesis in TNBC (170). Yang et al (171) demonstrated the involvement of POU domain class 3 transcription factor 3 (POU3F3) in inhibiting apoptosis and promoting proliferation in TNBC (171). Nuclear paraspeckle assembly transcript 1 (NEAT1) plays a role in TNBC metastasis (172-174). Some lncRNAs (HOTAIR, LncRNA-ATB, LincRNA-ROR) are known to be co-expressed with transcription factors involved in EMT and proliferation (175). Vaidya et al (176) demonstrated that nanoparticle-mediated transfer of RNA interference molecules targeting differentiation antagonizing non-protein coding RNA, a lncRNA that is enriched in TNBC, showed some efficacy in a murine xenograft model of TNBC (Table III). These studies have shed light on the use of antisense oligonucleotides against oncogenic lncRNA as a potential approach to TNBC therapy.

\section{Conclusions}

TNBC is associated with poor prognosis compared to other breast cancer subtypes, and its treatment remains challenging. New technology and tools have provided insight into the molecular mechanism of the disease. This knowledge has led to the identification of druggable targets and the development of biomarker-driven therapy. The FDA-approved drugs for TNBC to date include PARP inhibitors for patients with BRCA1/2 mutations and atezolizumab for PD- $\mathrm{L1}^{+}$tumors. Emerging targeted therapies have given hope for the treatment of TNBC. The inclusion of immunotherapy has shown promising results. Additionally, attempts to identify combinations that work effectively against TNBC are ongoing. A combination of the molecular profiles, including non-coding RNA and histology, has improved the prognosis and guided the treatment for TNBC.

\section{Acknowledgements}

The authors would like to thank Dr Raksha Rao K. (Institute of Bioinformatics and Applied Biotechnology, Bengaluru, Karnataka, India) for the critical reading of the manuscript and suggestions.

\section{Funding}

Financial support was provided by The Department of Science and Technology Fund for Improvement of S\&T Infrastructure in Higher Educational Institutions (grant no.SR/FST/LSI-5361/2012), The Department of Biotechnology, India, Glue grant (BTIPR23078/MED/29/1253/2017), and The Departments Information Technology, Biotechnology and Science and Technology, Government of Karnataka, India. MM is supported by The Senior Research Fellowship from Department of Science and Technology-Innovation in Science Pursuit for Inspired Research, India (DST/INSPIRE Fellowship/2016/IF160535).

\section{Availability of data and materials}

Not applicable.

\section{Authors' contributions}

$\mathrm{MM}$ and $\mathrm{BC}$ conceived the article, performed the literature search and data analysis, drafted and critically revised the work, and confirm the authenticity of the raw data. All authors read and approved the final manuscript.

\section{Ethics approval and consent to participate}

Not applicable.

\section{Patient consent for publication}

Not applicable.

\section{Competing interests}

The authors declare that they have no competing interests. 


\section{References}

1. Hwang SY, Park S and Kwon Y: Recent therapeutic trends and promising targets in triple negative breast cancer. Pharmacol Ther 199: 30-57, 2019.

2. Sung H, Ferlay J, Siegel RL, Laversanne M, Soerjomataram I, Jemal A and Bray F: Global cancer statistics 2020: GLOBOCAN estimates of incidence and mortality worldwide for 36 cancers in 185 countries. CA Cancer J Clin: Feb 4, 2021 (Epub ahead of print). doi: $10.3322 /$ caac. 21660

3. Perue CM, Sorlie T, Elsen MB, van de Rijn M, Jeffrey S and Rees C: Molecular portraits of human breast tumors. Nature 406: 747-52, 2000

4. Penault-Llorca F and Viale G: Pathological and molecular diagnosis of triple-negative breast cancer: A clinical perspective. Ann Oncol 23: vi19-vi22, 2012.

5. Yeh IT and Mies C: Application of immunohistochemistry to breast lesions. Arch Pathol Lab Med 132: 349-358, 2008.

6. Fedele M, Cerchia L and Chiappetta G: The epithelial-to-mesenchymal transition in breast cancer: Focus on basal-like carcinomas. Cancers 9: 134, 2017.

7. Dias K, Dvorkin-Gheva A, Hallett RM, Wu Y, Hassell J, Pond GR, Levine M, Whelan T and Bane AL: Claudin-low breast cancer; clinical \& pathological characteristics. PLoS One 12 : e0168669, 2017.

8. Spigel DR and Burstein HJ: HER2 overexpressing metastatic breast cancer. Curr Treat Options Oncol 3: 163-174, 2002.

9. Sorlie T, Tibshirani R, Parker J, Hastie T, Marron JS, Nobel A, Deng S, Johnsen H, Pesich R, Geisler S, et al: Repeated observation of breast tumor subtypes in independent gene expression data sets. Proc Natl Acad Sci USA 100: 8418-8423, 2003.

10. Hu Z, Fan C, Oh DS, Marron JS, He X, Qaqish BF, Livasy C, Carey LA, Reynolds E, Dressler L, et al: The molecular portraits of breast tumors are conserved across microarray platforms. BMC Genomics 7: 96, 2006.

11. Wang Q, Xu M, Sun Y, Chen J, Chen C, Qian C, Chen Y, Cao L, $\mathrm{Xu} Q$, Du X and Yang W: Gene expression profiling for diagnosis of triple-negative breast cancer: A multicenter, retrospective cohort study. Front Oncol 9: 354, 2019.

12. Slamon D, Eiermann W, Robert N,Pienkowski T, Martin M, Press M, Mackey J, Glaspy J, Chan A, Pawlicki M, et al: Adjuvant trastuzumab in HER2-positive breast cancer. N Engl J Med 365: 1273-1283, 2011

13. Marotti JD, de Abreu FB, Wells WA and Tsongalis GJ Triple-negative breast cancer: Next-generation sequencing for target identification. Am J Pathol 187: 2133-2138, 2017.

14. Reis-Filho JS and Tutt ANJ: Triple negative tumours: A critical review. Histopathology 52: 108-118, 2008.

15. Kaplan HG, Malmgren JA and Atwood M: T1N0 triple negative breast cancer: Risk of recurrence and adjuvant chemotherapy. Breast J 15: 454-460, 2009.

16. Chang-Qing Y, Jie L, Shi-Qi Z, Kun Z, Zi-Qian G, Ran X, Hui-Meng L, Ren-Bin Z, Gang Z, Da-Chuan Y and Chen-Yan Z: Recent treatment progress of triple negative breast cancer. Prog Biophys Mol Biol 151: 40-53, 2020.

17. Weigelt B and Reis-Filho JS: Histological and molecular types of breast cancer: Is there a unifying taxonomy? Nat Rev Clin Oncol 6: 718, 2009.

18. Shah SP, Roth A, Goya R, Oloumi A, Ha G, Zhao Y, Turashvili G, Ding J, Tse K, Haffari G, et al: The clonal and mutational evolution spectrum of primary triple-negative breast cancers. Nature 486: 395-399, 2012.

19. Malhotra GK, Zhao X, Band H and Band V: Histological, molecular and functional subtypes of breast cancers. Cancer Biol Ther 10: 955-960, 2010

20. Balkenhol MC, Vreuls W, Wauters CA, Mol SJ, van der Laak JA and Bult P: Histological subtypes in triple negative breast cancer are associated with specific information on survival. Ann Diagn Pathol 46: 151490, 2020.

21. Romero P, Benhamo V, Deniziaut G, Fuhrmann L, Berger F, Manié E, Bhalshankar J, Vacher S, Laurent C, Marangoni E, et al: Medullary breast carcinoma, a triple-negative breast cancer associated with BCLG overexpression. Am J Pathol 188: 2378-2391, 2018.

22. Huober J, Gelber S, Thurlimann B, Goldhirsch A, Coates AS Viale G, Öhlschlegel C, Price KN, Gelber RD, Regan MM and Thürlimann B: Prognosis of medullary breast cancer: Analyses of 13 International Breast Cancer Study Group (IBCSG) trials. Ann Oncol 23: 2843-2851, 2012.

23. Geyer FC, Weigelt B, Natrajan R, Lambros MB, de Biase D, Vatcheva R, Savage K, Mackay A, Ashworth A and Reis-Filho JS: Molecular analysis reveals a genetic basis for the phenotypic diversity of metaplastic breast carcinomas. J Pathol 220: 562-573, 2010
24. Hennessy BT, Gonzalez-Angulo AM, Stemke-Hale K, Gilcrease MZ, Krishnamurthy S, Lee JS, Fridlyand J, Sahin A, Agarwal R, Joy C, et al: Characterization of a naturally occurring breast cancer subset enriched in epithelial-to-mesenchymal transition and stem cell characteristics. Cancer Res 69: 4116-4124, 2009.

25. Hayes MJ, Thomas D, Emmons A, Giordano TJ and Kleer CG: Genetic changes of Wnt pathway genes are common events in metaplastic carcinomas of the breast. Clin Cancer Res 14: 4038-4044, 2008.

26. Thomas DN, Asarian A and Xiao P: Adenoid cystic carcinoma of the breast. J Surg Case Rep 2019: rjy355, 2019.

27. Ichikawa K, Mizukami Y, Takayama T, Takemura A, Miyati T and Taniya T: A case of adenoid cystic carcinoma of the breast. J Med Ultrasonics 34: 193-196, 2007.

28. Sun JY, Wu SG, Chen SY, Li FY, Lin HX, Chen YX and He ZY: Adjuvant radiation therapy and survival for adenoid cystic carcinoma of the breast. Breast 31: 214-218, 2017.

29. Aktepe F, Sarsenov D and Özmen V: Secretory carcinoma of the breast. J Breast Health 12: 174, 2016

30. Li L, Wu N, Li F, Li L, Wei L and Liu J: Clinicopathologic and molecular characteristics of 44 patients with pure secretory breast carcinoma. Cancer Biol Med 16: 139, 2019.

31. Pareja F, Geyer FC, Marchiò C, Burke KA, Weigelt B and Reis-Filho JS: Triple-negative breast cancer: The importance of molecular and histologic subtyping, and recognition of low-grade variants. NPJ Breast Cancer 2: 16036, 2016.

32. Kuroda H, Sakamoto G, Ohnisi K and Itoyama S: Clinical and pathological features of glycogen-rich clear cell carcinoma of the breast. Breast Cancer 12: 189-195, 2005.

33. Geyer FC, Pareja F, Weigelt B, Rakha E, Ellis IO, Schnitt SJ and Reis-Filho JS: The spectrum of triple-negative breast disease: High-and low-grade lesions. Am J Pathol 187: 2139-2151, 2017.

34. Degnim AC, Brahmbhatt RD, Radisky DC, Hoskin TL, Stallings-Mann M, Laudenschlager M, Mansfield A, Frost MH, Murphy L, Knutson K and Visscher DW: Immune cell quantitation in normal breast tissue lobules with and without lobulitis. Breast Cancer Res Treat 144: 539-549, 2014.

35. Aaltomaa S, Lipponen P, Eskelinen M, Kosma VM, Marin S, Alhava E and Syrjänen K: Lymphocyte infiltrates as a prognostic variable in female breast cancer. Eur J Cancer 28: 859-864, 1992.

36. Matsumoto H, Koo S, Dent R, Tan PH and Iqbal J: Role of inflammatory infiltrates in triple negative breast cancer. J Clin Pathol 68: 506-510, 2015.

37. Fridman WH, Galon J, Pagès F, Tartour E, Sautès-Fridman C and Kroemer G: Prognostic and predictive impact of intra-and peritumoral immune infiltrates. Cancer Res 71: 5601-5605, 2011.

38. Karn T, Jiang T, Hatzis C, Sänger N, El-Balat A, Holtrich U, Becker S, Bianchini G and Pusztai L: Abstract S1-07: Immune sculpting of the triple negative breast cancer genome. Cancer Res: 77, 2017 doi: 10.1158/1538-7445.SABCS16-S1-07.

39. Bottai G, Raschioni C, Losurdo A, Di Tommaso L, Tinterri C, Torrisi R, Reis-Filho JS, Roncalli M, Sotiriou C, Santoro A, et al: An immune stratification reveals a subset of PD-1/LAG-3 double-positive triple-negative breast cancers. Breast Cancer Res 18: 121, 2016.

40. Gruosso T, Gigoux M, Bertos N, Manem VSK, Guiot MC, Buisseret L, Salgado R, Van den Eyden G, Haibe-Kains B and Park M: Distinct immune microenvironments stratify triple-negative breast cancer and predict outcome. Ann Oncol 28: i16, 2017.

41. Abramson VG, Lehmann BD, Ballinger TJ and Pietenpol JA: Subtyping of triple-negative breast cancer: Implications for therapy. Cancer 121: 8-16, 2015.

42. Lehmann BD and Pietenpol JA: Identification and use of biomarkers in treatment strategies for triple-negative breast cancer subtypes. J Pathol 232: 142-150, 2014.

43. Burstein MD, Tsimelzon A, Poage GM, Covington KR, Contreras A, Fuqua SA, Savage MI, Osborne CK, Hilsenbeck SG, Chang JC, et al: Comprehensive genomic analysis identifies novel subtypes and targets of triple-negative breast cancer. Clin Cancer Res 21: 1688-1698, 2015.

44. Ahn SG, Kim SJ, Kim C and Jeong J: Molecular classification of triple-negative breast cancer. J Breast Cancer 19: 223-230, 2016.

45. Liu YR, Jiang YZ, Xu XE, Yu KD, Jin X, Hu X, Zuo WJ, Hao S, Wu J, Liu GY, et al: Comprehensive transcriptome analysis identifies novel molecular subtypes and subtype-specific RNAs of triple-negative breast cancer. Breast Cancer Res 18: 33, 2016.

46. Yin L, Duan JJ, Bian XW and Yu S: Triple-negative breast cancer molecular subtyping and treatment progress. Breast Cancer Res 22: 61, 2020 . 
47. Curtis C, Shah SP, Chin SF, Turashvili G, Rueda OM, Dunning MJ, Speed D, Lynch AG, Samarajiwa S, Yuan Y, et al: The genomic and transcriptomic architecture of 2,000 breast tumours reveals novel subgroups. Nature 486: 346-352, 2012.

48. Venkitaraman AR: Linking the cellular functions of BRCA genes to cancer pathogenesis and treatment. Ann Rev Pathol 4: 461-487, 2009.

49. Atchley DP, Albarracin CT, Lopez A, Valero V, Amos CI, Gonzalez-Angulo AM, Hortobagyi GN and Arun BK: Clinical and pathologic characteristics of patients with BRCA-positive and BRCA-negative breast cancer. J Clin Oncol 26: 4282-4288, 2008.

50. Foulkes WD, Stefansson IM, Chappuis PO, Bégin LR, Goffin JR, Wong N, Trudel M and Akslen LA: Germline BRCA1 mutations and a basal epithelial phenotype in breast cancer. J Natl Cancer Inst 95: 1482-1485, 2003.

51. Cancer Genome Atlas Network: Comprehensive molecular portraits of human breast tumours. Nature 490: 61-70, 2012.

52. Antoniou A, Pharoah PD, Narod S, Risch HA, Eyfjord JE, Hopper JL, Loman N, Olsson H, Johannsson O, Borg A, et al: Average risks of breast and ovarian cancer associated with BRCA1 or BRCA2 mutations detected in case series unselected for family history: A combined analysis of 22 studies. Am J Hum Genet 72: 1117-1130, 2003.

53. Turner N, Tutt A and Ashworth A: Hallmarks of 'BRCAness' in sporadic cancers. Nat Rev Cancer 4: 814-819, 2004.

54. Lord CJ and Ashworth A: BRCAness revisited. Nat Rev Cancer 16: 110-120, 2016

55. Bertucci F, Ng CK, Patsouris A, Droin N, Piscuoglio S, Carbuccia N, Soria JC, Dien AT, Adnani Y, Kamal M, et al: Genomic characterization of metastatic breast cancers Nature 569: 560-564, 2019.

56. Jiang YZ, Ma D, Suo C, Shi J, Xue M, Hu X, Xiao Y, Yu KD, Liu YR, Yu Y, et al: Genomic and transcriptomic landscape of triple-negative breast cancers: Subtypes and treatment strategies. Cancer Cell 35: 428-440.e5, 2019

57. Nik-Zainal S, Davies H, Staaf J, Ramakrishna M, Glodzik D, Zou X, Martincorena I, Alexandrov LB, Martin S Wedge DC, et al: Landscape of somatic mutations in 560 breast cancer whole-genome sequences. Nature 534: 47-54, 2016.

58. Bianchini G, Balko JM, Mayer IA, Sanders ME and Gianni L: Triple-negative breast cancer: Challenges and opportunities of a heterogeneous disease. Nat Rev Clin Oncol 13: 674-690, 2016.

59. Zhao Y, Sheng M, Zheng L, Xiong D, Yang K and Luo Y: Application of circulating tumor DNA in breast cancer. Breast J 26: 1797-1800, 2020

60. Lustberg MB, Stover DG and Chalmers JJ: Implementing liquid biopsies in clinical trials: State of affairs, opportunities and challenges. Cancer J 24: 61-64, 2018.

61. Thompson AM and Moulder-Thompson SL: Neoadjuvant treatment of breast cancer. Ann Oncol 23 (Suppl 10): x231-x236, 2012

62. Stover DG, Parsons HA, Ha G, Freeman SS, Barry WT, Guo H, Choudhury AD, Gydush G, Reed SC, Rhoades J, et al: Association of cell-free DNA tumor fraction and somatic copy number alterations with survival in metastatic triple-negative breast cancer. J Clin Oncol 36: 543-553, 2018.

63. Bidard FC, Peeters DJ, Fehm T, Nolé F, Gisbert-Criado R, Mavroudis D, Grisanti S, Generali D, Garcia-Saenz JA, Stebbing J, et al: Clinical validity of circulating tumour cells in patients with metastatic breast cancer: A pooled analysis of individual patient data. Lancet Oncol 15: 406-414, 2014.

64. Cristofanilli M, Pierga JY, Reuben J, Rademaker A, Davis AA, Peeters DJ, Fehm T, Nolé F, Gisbert-Criado R, Mavroudis D, et al: The clinical use of circulating tumor cells (CTCs) enumeration for staging of metastatic breast cancer (MBC): International expert consensus paper. Crit Rev Oncol Hematol 134: 39-45, 2019.

65. Riva F, Bidard FC, Houy A, Saliou A, Madic J, Rampanou A, Hego C, Milder M, Cottu P, Sablin MP, et al: Patient-specific circulating tumor DNA detection during neoadjuvant chemotherapy in triple-negative breast cancer. Clin Chem 63: 691-699, 2017.

66. Radovich M, Jiang G, Chitambar C, Nanda R, Falkson C, Lynce FC, Gallagher C, Isaacs C, Blaya M, Paplomata E, et al: Abstract GS5-02: Detection of circulating tumor DNA (ctDNA) after neoadjuvant chemotherapy is significantly associated with disease recurrence in early-stage triple-negative breast cancer (TNBC): Preplanned correlative results from clinical trial BRE12-158. Cancer Res: 80, 2020 doi: 10.1158/1538-7445. SABCS19-GS5-02.

67. Becker S: A historic and scientific review of breast cancer: The next global healthcare challenge. Int J Gynecol Obstet 131 (Suppl 1): S36-S39, 2015.
68. .Blum JL, Flynn PJ, Yothers G, Asmar L, Geyer CE Jr, Jacobs SA, Robert NJ, Hopkins JO, O'Shaughnessy JA, Dang CT, et al: Anthracyclines in early breast cancer: The ABC Trials-USOR 06-090, NSABP B-46-I/USOR 07132, and NSABP B-49 (NRG Oncology). J Clin Oncol 35: 2647-2655, 2017.

69. Mansel RE, Fodstad O and Jiang WG: Metastasis of breast cancer. Springer, 2007.

70. Mosca L, Ilari A, Fazi F, Assaraf YG and Colotti G: Taxanes in cancer treatment: Activity, chemoresistance and its overcoming. Drug Resist Updat 54: 100742, 2021.

71. Bachegowda LS, Makower DF and Sparano JA: Taxanes: Impact on breast cancer therapy. Anticancer Drugs 25: 512-521, 2014

72. Cortazar P, Zhang L, Untch M, Mehta K, Costantino JP, Wolmark N, Bonnefoi H, Cameron D, Gianni L, Valagussa P, et al: Pathological complete response and long-term clinical benefit in breast cancer: The CTNeoBC pooled analysis. Lancet 384: 164-172, 2014.

73. Von Minckwitz G, Untch M, Blohmer JU, Costa SD, Eidtmann H, Fasching PA, Gerber B, Eiermann W, Hilfrich J, Huober J, et al: Definition and impact of pathologic complete response on prognosis after neoadjuvant chemotherapy in various intrinsic breast cancer subtypes. J Clin Oncol 30: 1796-1804, 2012.

74. Liedtke C, Mazouni C, Hess KR, André F, Tordai A, Mejia JA, Symmans WF, Gonzalez-Angulo AM, Hennessy B, Green M, et al: Response to neoadjuvant therapy and long-term survival in patients with triple-negative breast cancer. J Clin Oncol 26: 1275-1281, 2008.

75. Park JH, Ahn JH and Kim SB: How shall we treat early triple-negative breast cancer (TNBC): From the current standard to upcoming immuno-molecular strategies. ESMO Open 3: $\mathrm{e} 000357,2018$.

76. Greene J and Hennessy B: The role of anthracyclines in the treatment of early breast cancer. J Oncol Pharm Pract 21: 201-212, 2015.

77. Park JS, Jeung HC, Rha SY, A hn JB, Kang B, Chon HJ, Hong MH, Lim S, Yang WI, Nam CM and Chung HC: Phase II gemcitabine and capecitabine combination therapy in recurrent or metastatic breast cancer patients pretreated with anthracycline and taxane. Cancer Chemother Pharmacol 74: 799-808, 2014.

78. Karachaliou N,Ziras N, Syrigos K, Tryfonidis K, Papadimitraki E, Kontopodis E, Bozionelou V, Kalykaki A, Georgoulias V and Mavroudis D: A multicenter phase II trial of docetaxel and capecitabine as salvage treatment in anthracycline-and taxane-pretreated patients with metastatic breast cancer. Cancer Chemother Pharmacol 70: 169-176, 2012.

79. Anton A, Lluch A, Casado A, Provencio M, Muñoz M, Lao J, Bermejo B, Paules AB, Gayo J and Martin M: Phase I study of oral vinorelbine and capecitabine in patients with metastatic breast cancer. Anticancer Res 30: 2255-2261, 2010.

80. Kennedy RD, Quinn JE, Mullan PB, Johnston PG and Harkin DP: The role of BRCA1 in the cellular response to chemotherapy. J Natl Cancer Inst 96: 1659-1668, 2004.

81. Huang L, Liu Q, Chen S and Shao Z: Cisplatin versus carboplatin in combination with paclitaxel as neoadjuvant regimen for triple negative breast cancer. Onco Targets Ther 10: 5739-5744, 2017.

82. Isakoff SJ, Mayer EL, He L, Traina TA, Carey LA, Krag KJ, Rugo HS, Liu MC, Stearns V, Come SE, et al: TBCRC009: A multicenter phase II clinical trial of platinum monotherapy with biomarker assessment in metastatic triple-negative breast cancer. J Clin Oncol 33: 1902-1909, 2015.

83. Byrski T, Dent R, Blecharz P, Foszczynska-Kloda M, Gronwald J, Huzarski T, Cybulski C, Marczyk E, Chrzan R, Eisen A, et al: Results of a phase II open-label, non-randomized trial of cisplatin chemotherapy in patients with BRCA1-positive metastatic breast cancer. Breast Cancer Res 14: R110, 2012.

84. Isakoff SJ: Triple negative breast cancer: Role of specific chemotherapy agents. Cancer J 16: 53-61, 2010.

85. Kim GM, Jeung HC, Jung KH, Kim HJ, Lee KH, Park KH, Lee JE, Anh MS, Kohn S, Lee SS, et al: PEARLY: A randomized, multicenter, open-label, phase III trial comparing anthracyclines followed by taxane versus anthracyclines followed by taxane plus carboplatin as (neo) adjuvant therapy in patients with early triple-negative breast cancer. J Clin Oncol 35: (15_suppl): TPS587-TPS587, 2017.

86. Chen XS, Nie XQ, Chen CM, Wu JY, Wu J, Lu JS, Shao ZM, Shen ZZ and Shen KW: Weekly paclitaxel plus carboplatin is an effective nonanthracycline-containing regimen as neoadjuvant chemotherapy for breast cancer. Ann Oncol 21: 961-967, 2010.

87. Sawyers C: Targeted cancer therapy. Nature 432: 294-297, 2004

88. Dancey JE and Chen HX: Strategies for optimizing combinations of molecularly targeted anticancer agents. Nat Rev Drug Dis 5: 649-659, 2006. 
89. Jhan JR and Andrechek ER: Triple-negative breast cancer and the potential for targeted therapy. Pharmacogenomics 18 : 1595-1609, 2017.

90. Audebert M, Salles B and Calsou P: Involvement of poly (ADP-ribose) polymerase-1 and XRCC1/DNA ligase III in an alternative route for DNA double-strand breaks rejoining. J Biol Chem 279: 55117-55126, 2004.

91. Shall S and de Murcia G: Poly(ADP-ribose) polymerase-1: What have we learned from the deficient mouse model? Mutat Res 460: 1-15, 2000.

92. Farmer H, McCabe N, Lord CJ, Tutt AN, Johnson DA, Richardson TB, Santarosa M, Dillon KJ, Hickson I, Knights C, et al: Targeting the DNA repair defect in BRCA mutant cells as a therapeutic strategy. Nature 434: 917-921, 2005

93. Bryant HE, Schultz N, Thomas HD, Parker KM, Flower D, Lopez E, Kyle S, Meuth M, Curtin NJ and Helleday T: Specific killing of BRCA2-deficient tumours with inhibitors of poly(ADP-ribose) polymerase. Nature 434: 913-917, 2005.

94. Turner N, Tutt A and Ashworth A: Targeting the DNA repair defect of BRCA tumours. Curr Opin Pharmacol 5: 388-393, 2005.

95. Turner NC, Lord CJ, Iorns E, Brough R, Swift S, Elliott R Rayter S, Tutt AN and Ashworth A: A synthetic lethal siRNA screen identifying genes mediating sensitivity to a PARP inhibitor. EMBO J 27: 1368-1377, 2008.

96. Calabrese CR, Almassy R, Barton S, Batey MA, Calvert AH, Canan-Koch S, Durkacz BW, Hostomsky Z, Kumpf RA, Kyle S, et al: Anticancer chemosensitization and radiosensitization by the novel poly(ADP-ribose) polymerase-1 inhibitor AG14361. J Natl Cancer Inst 96: 56-67, 2004.

97. Robson ME, Im SA, Senkus E, Xu B, Domchek SM, Masuda N, Delaloge S, Li W, Tung NM, Armstrong A, et al: OlympiAD: Phase III trial of olaparib monotherapy versus chemotherapy for patients (pts) with HER2-negative metastatic breast cancer (mBC) and a germline BRCA mutation (gBRCAm). J Clin Oncol: 35, 2017.

98. Robson ME, Tung N, Conte P, Im SA, Senkus E, Xu B, Masuda N, Delaloge S, Li W, Armstrong A, et al: OlympiAD final overall survival and tolerability results: Olaparib versus chemotherapy treatment of physician's choice in patients with a germline BRCA mutation and HER2-negative metastatic breast cancer. Ann Oncol 30: 558-566, 2019.

99. Litton JK, Rugo HS, Ettl J, Hurvitz SA, Gonçalves A, Lee KH, Fehrenbacher L, Yerushalmi R, Mina LA, Martin M, et al: Talazoparib in patients with advanced breast cancer and a germline BRCA mutation. N Engl J Med 379: 753-763, 2018.

100. Poggio F, Bruzzone M, Ceppi M, Conte B, Martel S, Maurer C, Tagliamento M, Viglietti G, Del Mastro L, de Azambuja E and Lambertini M: Single-agent PARP inhibitors for the treatment of patients with BRCA-mutated HER2-negative metastatic breast cancer: A systematic review and meta-analysis. ESMO Open 3: e000361, 2018.

101. Miller K, Tong Y, Jones DR, Walsh T, Danso MA MaPaula Silverman CX, King MC, Badve SS and Perkins SM: Cisplatin with or without rucaparib after preoperative chemotherapy in patients with triple negative breast cancer: Final efficacy results of Hoosier Oncology Group BRE09-146. J Clin Oncol 33: 1082, 2015 .

102. Isakoff SJ, Puhalla S, Domchek SM, Friedlander M, Kaufman B, Robson M, Telli ML, Diéras V, Han HS, Garber JE, et al: A randomized phase II study of veliparib with temozolomide or carboplatin/paclitaxel versus placebo with carboplatin/paclitaxel in BRCA1/2 metastatic breast cancer: Design and rationale Future Oncol 13: 307-320, 2017

103. Zimmer AS, Gillard M, Lipkowitz S and Lee JM: Update on PARP inhibitors in breast cancer. Curr Treat Options Oncol 19: 21, 2018

104. Rugo HS Olopade OI, DeMichele A, Yau C, van 't Veer LJ, Buxton MB, Hogarth M, Hylton NM, Paoloni M, Perlmutter J, et al: Adaptive randomization of veliparib-carboplatin treatment in breast cancer. N Engl J Med 375: 23-34, 2016

105. Domchek SM, Postel-Vinay S, Im SA, Hee Park Y, Delord JP, Italiano A, Alexandre J, You B, Bastian S, Krebs MG, et al: Abstract PD5-04: An open-label, phase II basket study of olaparib and durvalumab (MEDIOLA): Updated results in patients with germline BRCA-mutated (gBRCAm) metastatic breast cancer (MBC). Cancer Res: 79, 2019 doi: 10.1158/1538-7445. SABCS18-PD5-04.

106. Tutt A, Kaufman B, Gelber RD, McFadden E, Goessl C Viale G, Geyer G, Zardavas D, Arahmani A, Fumagalli D, et al: OlympiA: A randomized phase III trial of olaparib as adjuvant therapy in patients with high-risk HER2-negative breast cancer (BC) and a germline BRCA1/2 mutation (gBRCAm). Ann Oncol 28: V67, 2017
107. Earl HM, Vallier AL, Qian W, Grybowicz L, Thomas S, Mahmud S, Harvey C, McAdam K, Hughes-Davies L, Roylance R, et al: PARTNER: Randomised, phase II/III trial to evaluate the safety and efficacy of the addition of olaparib to platinum-based neoadjuvant chemotherapy in triple negative and/or germline BRCA mutated breast cancer patients. J Clin Oncol 35: TPS591, 2017.

108. Cantley LC: The phosphoinositide 3-kinase pathway. Science 296: 1655-1657, 2002

109. Engelman JA: Targeting PI3K signalling in cancer: Opportunities, challenges and limitations. Nat Rev Cancer 9: 550-562, 2009.

110. Delaloge S and DeForceville L: Targeting PI3K/AKT pathway in triple-negative breast cancer. Lancet Oncol 18: 1293-1294, 2017.

111. Katso R, Okkenhaug K, Ahmadi K, White S, Timms J and Waterfield MD: Cellular function of phosphoinositide 3-kinases: Implications for development, immunity, homeostasis, and cancer. Annu Rev Cell Dev Biol 17: 615-675, 2001.

112. Kim SB, Dent R, Im SA, Espié M, Blau S, Tan AR, Isakoff SJ, Oliveira M, Saura C, Wongchenko MJ, et al: Ipatasertib plus paclitaxel versus placebo plus paclitaxel as first-line therapy for metastatic triple-negative breast cancer (LOTUS): A multicentre, randomised, double-blind, placebo-controlled, phase 2 trial. Lancet Oncol 18: 1360-1372, 2017.

113. Martín M, Chan A, Dirix L, O'Shaughnessy J, Hegg R, Manikhas A, Shtivelband M, Krivorotko P, Batista López N, Campone M, et al: A randomized adaptive phase II/III study of buparlisib, a pan-class I PI3K inhibitor, combined with paclitaxel for the treatment of HER2-advanced breast cancer (BELLE-4). Ann Oncol 28: 313-320, 2017.

114. Schmid P, Cortes J, Robson ME, Iwata H, Hegg R, Nechaeva M, Xu B, Verma S, Haddad V, Imedio R, et al: A phase III trial of capivasertib and paclitaxel in first-line treatment of patients with metastatic triple-negative breast cancer (CAPItello290). J Clin Oncol 38: TPS1109, 2020.

115. Schmid P, Abraham J, Chan S, Wheatley D, Brunt M, Nemsadze G, Baird R, Park YH, Hall P, Perren T, et al: AZD5363 plus paclitaxel versus placebo plus paclitaxel as first-line therapy for metastatic triple-negative breast cancer (PAKT): A randomised, double-blind, placebo-controlled, phase II trial. J Clin Oncol 36: 1007, 2018.

116. Gonzalez-Angulo AM, Green MC, Murray JL, Palla SL, Koenig KH, Valero BrewsterV AM, Ibrahim NK, Moulder SL, Litton JK, Crawford DJ, et al: Open label, randomized clinical trial of standard neoadjuvant chemotherapy with paclitaxel followed by FEC (T-FEC) versus the combination of paclitaxel and RAD001 followed by FEC (TR-FEC) in women with triple receptor-negative breast cancer (TNBC). J Clin Oncol 29: 1016, 2011.

117. Basho RK, Gilcrease M, Murthy RK, Helgason T, Karp DD, Meric-Bernstam F, Hess KR, Herbrich SM, Valero V, Albarracin $\mathrm{C}$, et al: Targeting the PI3K/AKT/mTOR pathway for the treatment of mesenchymal triple-negative breast cancer: Evidence from a phase 1 trial of mTOR inhibition in combination with liposomal doxorubicin and bevacizumab. JAMA Oncol 3: 509-515, 2017.

118. Kim Y, Jae E and Yoon M: Influence of androgen receptor expression on the survival outcomes in breast cancer: A meta-analysis. J Breast Cancer 18: 134-142, 2015.

119. Gucalp A, Tolaney S, Isakoff SJ, Ingle JN, Liu MC, Carey LA Blackwell K, Rugo H, Nabell L, Forero A, et al: Phase II trial of bicalutamide in patients with androgen receptor-positive, estrogen receptor-negative metastatic breast cancer. Clin Cancer Res 19: 5505-5512, 2013.

120. Traina TA, Miller K, Yardley DA, Eakle J, Schwartzberg LS, O'Shaughnessy J, Gradishar W, Schmid P, Winer E, Kelly C, et al: Enzalutamide for the treatment of androgen receptor-expressing triple-negative breast cancer. J Clin Oncol 36: 884-890, 2018.

121. Traina TA, Miller K, Yardley DA, O'Shaughnessy J, Cortes J, Kelly AACM, Trudeau ME, Schmid P, Gianni L, García-Estevez A, et al: Results from a phase 2 study of enzalutamide (ENZA), an androgen receptor (AR) inhibitor, in advanced $\mathrm{AR}+$ triple-negative breast cancer (TNBC). J Clin Oncol 33: 1003, 2015.

122. Lehmann BD, Bauer JA, Schafer JM, Pendleton CS, Tang L, Johnson KC, Chen X, Balko JM, Gómez H, Arteaga CL, et al: PIK3CA mutations in androgen receptor-positive triple negative breast cancer confer sensitivity to the combination of PI3K and androgen receptor inhibitors. Breast Cancer Res 16: 406, 2014. 
123. Lehmann BD, Abramson VG, Sanders ME, Mayer EL, Haddad TC, Nanda R, Van Poznak C, Storniolo AM, Nangia JR, Gonzalez-Ericsson PI, et al: TBCRC 032 IB/II multicenter study: Molecular insights to AR antagonist and PI3K inhibitor efficacy in patients with AR+ metastatic triple-negative breast cancer. Clin Cancer Res 26: 2111-2123, 2020.

124. Panowski S, Bhakta S, Raab H, Polakis P and Junutula JR: Site-specific antibody drug conjugates for cancer therapy. MAbs 6: 34-45, 2014.

125. Nejadmoghaddam MR, Minai-Tehrani A, Ghahremanzadeh R, Mahmoudi M, Dinarvand R and Zarnani AH: Antibody-drug conjugates: Possibilities and challenges. Avicenna J Med Biotechnol 11: 3-23, 2019.

126. Goldenberg DM, Stein R and Sharkey RM: The emergence of trophoblast cell-surface antigen 2 (TROP-2) as a novel cancer target. Oncotarget 9: 28989-29006, 2018.

127. Bardia A, Mayer IA, Vahdat LT, Tolaney SM, Isakoff SJ, Diamond JR, O'Shaughnessy J, Moroose RL, Santin AD, Abramson VG, et al: Sacituzumab govitecan-hziy in refractory metastatic triple-negative breast cancer. N Engl J Med 380: 741-751, 2019.

128. Liu Y, Lian W, Zhao X, Diao Y, Xu J, Xiao L, Qing Y, Xue T and Wang J: SKB264 ADC: A first-in-human study of SKB264 in patients with locally advanced unresectable/metastatic solid tumors who are refractory to available standard therapies. J Clin Oncol 38 (15_suppl): TPS3659, 2020.

129. Lyons TG: Targeted therapies for triple-negative breast cancer. Curr Treat Options Oncol 20: 82, 2019.

130. Giltnane JM and Balko JM: Rationale for targeting the Ras/MAPK pathway in triple-negative breast cancer. Dis Med 17: 275-283, 2014

131. Romanelli A, Clark A, Assayag F, Chateau-Joubert S, Poupon MF, Servely JL, Fontaine JJ, Liu X, Spooner E, Goodstal S, et al: Inhibiting aurora kinases reduces tumor growth and suppresses tumor recurrence after chemotherapy in patient-derived triple-negative breast cancer xenografts. Mol Cancer Ther 11: 2693-2703, 2012

132. Finn RS: Östrogenrezeptor-positiver Brustkrebs: Erfolgreiche Palbociblib-Letrozol-Kombination. Breast Cancer 375: 1925-1936, 2016.

133. Lucantoni F, Lindner AU, O'Donovan N, Düssmann H and Prehn JH: Systems modeling accurately predicts responses to genotoxic agents and their synergism with BCL-2 inhibitors in triple negative breast cancer cells. Cell Death Dis 9: 42, 2018

134. Inao T, Iida Y, Moritani T, Okimoto T, Tanino R, Kotani H and Harada M: Bcl-2 inhibition sensitizes triple-negative human breast cancer cells to doxorubicin. Oncotarget 9: 25545-25556, 2018.

135. Marra A, Viale G and Curigliano G: Recent advances in triple negative breast cancer: The immunotherapy era. BMC Med 17: $90,2019$.

136. Weber S, Traunecker A, Oliveri F, Gerhard W and Karjalainen K: Specific low-affinity recognition of major histocompatibility complex plus peptide by soluble T-cell receptor. Nature 356: 793-796, 1992.

137. Peggs KS, Quezada SA and Allison JP: Cancer immunotherapy: Co-stimulatory agonists and co-inhibitory antagonists. Clin Exp Immunol 157: 9-19, 2009.

138. Planes-Laine G, Rochigneux P, Bertucci F, Chrétien A-S, Viens P, Sabatier R and Gonçalves A: PD-1/PD-L1 targeting in breast cancer: The first clinical evidences are emerging. A literature review. Cancers (Basel) 11: 1033, 2019.

139. Mahoney KM, Rennert PD and Freeman GJ: Combination cancer immunotherapy and new immunomodulatory targets. Nat Rev Drug Dis 14: 561-584, 2015.

140. Alsaab HO, Sau S, Alzhrani R, Tatiparti K, Bhise K, Kashaw SK and Iyer AK: PD-1 and PD-L1 checkpoint signaling inhibition for cancer immunotherapy: Mechanism, combinations, and clinical outcome. Front Pharmacol 8: 561, 2017.

141. Sabatier R, Finetti P, Mamessier E, Adelaide J, Chaffanet M, Ali HR, Viens P, Caldas C, Birnbaum D and Bertucci F: Prognostic and predictive value of PDL1 expression in breast cancer. Oncotarget 6: 5449-5464, 2015

142. Mittendorf EA, Philips AV, Meric-Bernstam F, Qiao N, Wu Y, Harrington S, Su X, Wang Y, Gonzalez-Angulo AM, Akcakanat A, et al: PD-L1 expression in triple-negative breast cancer. Cancer Immunol Res 2: 361-370, 2014.

143. Patel SP and Kurzrock R: PD-L1 expression as a predictive biomarker in cancer immunotherapy. Mol Cancer Ther 14: 847-856, 2015.
144. Schmidt M, Böhm D, Von Törne C, Steiner E, Puhl A, Pilch H, Lehr HA, Hengstler JG, Kölbl H and Gehrmann M: The humoral immune system has a key prognostic impact in node-negative breast cancer. Cancer Res 68: 5405-5413, 2008.

145. Aguiar PN Jr, Santoro IL, Tadokoro H, de Lima Lopes G, Filardi BA, Oliveira P, Mountzios G and de Mello RA: The role of PD-L1 expression as a predictive biomarker in advanced non-small-cell lung cancer: A network meta-analysis. Immunotherapy 8: 479-488, 2016.

146. Beckers RK, Selinger CI, Vilain R, Madore J, Wilmott JS, Harvey K, Holliday A, Cooper CL, Robbins E, Gillett D, et al: Programmed death ligand 1 expression in triple-negative breast cancer is associated with tumour-infiltrating lymphocytes and improved outcome. Histopathology 69: 25-34, 2016.

147. Vagia E, Mahalingam D and Cristofanilli M: The landscape of targeted therapies in TNBC. Cancers (Basel 12: 916, 2020

148. Schmid P, Adams S, Rugo HS, Schneeweiss A, Barrios CH, Iwata H, Dieras V, Henschel V, Molinero L, Chui SY, et al: IMpassion130: Updated overall survival (OS) from a global, randomized, double-blind, placebo-controlled, Phase III study of atezolizumab (atezo)+ nab-paclitaxel (nP) in previously untreated locally advanced or metastatic triple-negative breast cancer (mTNBC). J Clin Oncol 37 (Suppl 15): S1003, 2019.

149. Cortés J, Lipatov O, Im SA, Gonçalves A, Lee KS, Schmid P, Tamura K, Testa L, Witzel I, Ohtani S, et al: LBA21 KEYNOTE-119: Phase III study of pembrolizumab (pembro) versus single-agent chemotherapy (chemo) for metastatic triple negative breast cancer (mTNBC). Ann Oncol 30: v859-v860, 2019.

150. Cortes J, Guo Z, Karantza V and Aktan G: Abstract CT069: KEYNOTE-355: Randomized, double-blind, phase III study of pembrolizumab plus chemotherapy vs placebo plus chemotherapy for previously untreated, locally recurrent, inoperable or metastatic triple-negative breast cancer (mTNBC). Cancer Res: 77, 2017 doi: 10.1158/1538-7445.AM2017-CT069.

151. Schmid P, Salgado R, Park YH, Muñoz-Couselo E, Kim SB, Sohn J, Im SA, Foukakis T, Kuemmel S, Dent R, et al: Pembrolizumab plus chemotherapy as neoadjuvant treatment of high-risk, early-stage triple-negative breast cancer: Results from the phase $1 \mathrm{~b}$ open-label, multicohort KEYNOTE-173 study. Ann Oncol 31: 569-581, 2020.

152. Barker AD, Sigman CC, Kelloff GJ, Hylton NM, Berry DA and Esserman LJ: I-SPY 2: An adaptive breast cancer trial design in the setting of neoadjuvant chemotherapy. Clin Pharmacol Ther 86: 97-100, 2009.

153. Keenan TE and Tolaney SM: Role of immunotherapy in Triple-negative breast cancer. J Natl Compr Canc Netw 18: 479-489, 2020.

154. Lin S and Gregory RI: MicroRNA biogenesis pathways in cancer. Nat Rev Cancer 15: 321-333, 2015.

155. Qattan A: Novel miRNA targets and therapies in the triple-negative breast cancer microenvironment: An emerging Hope for a challenging disease. Int J Mol Sci 21: 8905, 2020.

156. Si W, Shen J, Zheng H and Fan W: The role and mechanisms of action of microRNAs in cancer drug resistance. Clin Epigenetics 11: 25, 2019

157. Ding L, Gu H, Xiong X, Ao H, Cao J, Lin W, Yu M, Lin J and Cui Q: MicroRNAs involved in carcinogenesis, prognosis, therapeutic resistance, and applications in human triple-negative breast cancer. Cells 8: 1492, 2019.

158. Lyng MB, Lænkholm AV, Søkilde R, Gravgaard KH, Litman T and Ditzel HJ: Global microRNA expression profiling of high-risk $\mathrm{ER}+$ breast cancers from patients receiving adjuvant tamoxifen mono-therapy: A DBCG study. PLoS One 7: e36170, 2012.

159. Gorur A, Bayraktar R, Ivan C, Mokhlis HA, Bayraktar E, Kahraman N, Karakas D, Karamil S, Kabil NN, Kanlikilicer P, et al: ncRNA therapy with miRNA-22-3p suppresses the growth of triple-negative breast cancer. Mol Ther Nucleic Acids 23: 930-943, 2021.

160. Pang Y, Liu J, Li X, Xiao G, Wang H, Yang G, Li Y, Tang SC, Qin S, Du N, et al: MYC and DNMT 3A-mediated DNA methylation represses micro RNA-200b in triple negative breast cancer. J Cell Mol Med 22: 6262-6274, 2018.

161. Huang X, Taeb S, Jahangiri S, Emmenegger U, Tran E, Bruce J, Mesci A, Korpela E, Vesprini D, Wong CS, et al: miRNA-95 mediates radioresistance in tumors by targeting the sphingolipid phosphatase SGPP1. Cancer Res 73: 6972-6986, 2013.

162. Tormo E, Ballester S, Adam-Artigues A, Burgués O, Alonso E, Bermejo B, Menéndez S, Zazo S, Madoz-Gúrpide J, Rovira A, et al: The miRNA-449 family mediates doxorubicin resistance in triple-negative breast cancer by regulating cell cycle factors. Sci Rep 9: 5316, 2019. 
163. Naorem LD, Muthaiyan M and Venkatesan A: Identification of dysregulated miRNAs in triple negative breast cancer: A meta-analysis approach. J Cell Physiol 234: 11768-11779, 2019.

164. Malla RR, Kumari S, Gavara MM, Badana AK, Gugalavath S, Kumar DKG and Rokkam P: A perspective on the diagnostics, prognostics, and therapeutics of microRNAs of triple-negative breast cancer. Biophys Rev 11: 227-234, 2019.

165. Liu Y, Cai Q, Bao PP, Su Y, Cai H, Wu J, Ye F, Guo X, Zheng W, Zheng Y and Shu XO: Tumor tissue microRNA expression in association with triple-negative breast cancer outcomes. Breast Cancer Res Treat 152: 183-191, 2015.

166. Kahraman M, Röske A, Laufer T, Fehlmann T, Backes C, Kern F, Kohlhaas J, Schrörs H, Saiz A, Zabler C, et al: MicroRNA in diagnosis and therapy monitoring of early-stage triple-negative breast cancer. Sci Rep 8: 11584, 2018.

167. Mei J,Hao L, Wang H, Xu R, Liu Y, Zhu Y and Liu C: Systematic characterization of non-coding RNAs in triple-negative breast cancer. Cell Prolif 53: e12801, 2020.

168. Shu D, Li H, Shu Y, Xiong G, Carson WE III, Haque F, Xu R and Guo P: Systemic delivery of anti-miRNA for suppression of triple negative breast cancer utilizing RNA nanotechnology. ACS Nano 9: 9731-9740, 2015.

169. Yin H, Xiong G, Guo S, Xu C, Xu R, Guo P and Shu D: Delivery of anti-miRNA for triple-negative breast cancer therapy using RNA nanoparticles targeting stem cell marker CD133. Mol Ther 27: 1252-1261, 2019

170. Lin A, Li C, Xing Z, Hu Q, Liang K, Han L, Wang C, Hawke DH, Wang S, Zhang Y, et al: The LINK-A lncRNA activates normoxic HIF1 $\alpha$ signalling in triple-negative breast cancer. Nat Cell Biol 18: 213-224, 2016.
171. Yang J, Meng X, Yu Y, Pan L, Zheng Q and Lin W: LncRNA POU3F3 promotes proliferation and inhibits apoptosis of cancer cells in triple-negative breast cancer by inactivating caspase 9 . Biosci Biotechnol Biochem 83: 1117-1123, 2019.

172. Jiang X, Zhou Y, Sun AJ and Xue JL: NEAT1 contributes to breast cancer progression through modulating miR-448 and ZEB1. J Cell Physiol 233: 8558-8566, 2018.

173. Ke H, Zhao L, Feng X, Xu H, Zou L, Yang Q, Su X, Peng L and Jiao B: NEAT1 is required for survival of breast cancer cells through FUS and miR-548. Gene Regul Syst Biol 10 (Suppl 1): S11-S17, 2016

174. Wang LI, Liu D, Wu X, Zeng Y, Li L, Hou Y, Li W and Liu Z: Long non-coding RNA (LncRNA) RMST in triple-negative breast cancer (TNBC): Expression analysis and biological roles research. J Cell Physiol 233: 6603-6612, 2018.

175. Xu Q, Deng F, Qin Y, Zhao Z, Wu Z, Xing Z, Ji A and Wang QJ: Long non-coding RNA regulation of epithelialmesenchymal transition in cancer metastasis. Cell Death Dis 7: e2254, 2016.

176. Vaidya AM, Sun Z, Ayat N, Schilb A, Liu X, Jiang H, Sun D, Scheidt J, Qian V, He S, et al: Systemic delivery of tumor-targeting siRNA nanoparticles against an oncogenic LncRNA facilitates effective triple-negative breast cancer therapy. Bioconjug Chem 30: 907-919, 2019.

177. Sha S, Yuan D, Liu Y, Han B and Zhong N: Targeting long non-coding RNA DANCR inhibits triple negative breast cancer progression. Biol Open 6: 1310-1316, 2017. Attribution 4.0 International (CC BY 4.0) License. 